\title{
Article
}

\section{Dynamically Induced Anomalies of the Japan/East Sea Surface Temperature}

\author{
Olga Trusenkova*, Vyacheslav Lobanov, and Dmitry Kaplunenko \\ V.I. Il'ichev Pacific Oceanological Institute, Far Eastern Branch \\ Russian Academy of Sciences, Vladivostok 690041, Russia
}

\begin{abstract}
Variability of sea surface temperature (SST) in the Japan/East Sea (JES) was studied using complex empirical orthogonal function (CEOF) analysis. Two daily data sets were analyzed: (1) New Generation $0.05^{\circ}$-gridded SST from Tohoku University, Japan (July 2002-July 2006), and (2) $0.25^{\circ}$-gridded SST from the Japan Meteorological Agency (October 1993-November 2006). Linkages with wind stress curl were revealed using 6-h $1^{\circ}$-gridded surface zonal and meridional winds from ancillary data of the SeaWiFS Project, a special National Centers for Environmental Prediction/National Center for Atmospheric Research (NCEP/NCAR) product (1998-2005). SST anomalies (SSTA) were obtained by removing the seasonal signal, estimated as the leading mode of the CEOF decomposition of the original SST. Leading CEOF modes of residual SSTA obtained from both data sets were consistent with each other and were characterized by annual, semiannual, and quasi-biennial time scales estimated with $95 \%$ statistical significance. The Semiannual Mode lagged 2 months behind the increased occurrence of the anticyclonic (AC) wind stress curl over the JES. Links to dynamic processes were investigated by numerical simulations using an oceanic model. The suggested dynamic forcings of SSTA are the inflow of subtropical water into the JES through the Korea Strait, divergence in the surface layer induced by Ekman suction, meridional shifts of the Subarctic Front in the western JES, AC eddy formation, and wind-driven strengthening/weakening of large-scale currents. Events of west-east SSTA movement were identified in July-September. The SSTA moved from the northeastern JES towards the continental coast along the path of the westward branch of the Tsushima Current at a speed consistent with the advective scale.
\end{abstract}

Key words : moving anomalies, oceanic model, semiannual time-scale, wind-driven circulation, wind stress curl

\section{Introduction}

Research on large-scale variability of sea surface temperature (SST) has often focused on interannual and decadal time scales and on analyses of the SST relationships with atmospheric systems that affect air-sea heat exchange. Recent studies have shown that SST in the Japan/East Sea (JES) is affected by variations of the Siberian High (i.e., the East Asia winter monsoon), which, in turn, is related to the Arctic and North Atlantic oscillations (Minobe et al. 2004; Park and Chu 2006). SST variability in the JES has also been found to relate to that of the Aleutian Low, North Pacific High, and East

\footnotetext{
*Corresponding author. E-mail : trolia@poi.dvo.ru
}

Asian jet stream (Minobe et al. 2004; Park and Chu 2006). Park et al. (2005) conducted harmonic analyses of semi-monthly satellite-based SST to examine the seasonal signal of SST in the JES. The 12-month component accounted for $88-96 \%$ of the total SST variance, depending on the location. The amplitude of the seasonal signal was greater and the annual minimum occurred earlier in the northern JES than in the south. Spatial difference in the seasonal signal was attributed to differential cooling and variation of wind speed over the JES, i.e., spatial variability of the air-sea heat exchange (Park et al. 2005).

Semiannual variability has been revealed in oceanic and atmospheric variables around the JES. A 6-month signal was observed in the JES SST and shown to be especially strong northward of $43^{\circ} \mathrm{N}$ (Park and Chung 
1999). Semiannual variability was also detected in volume transport entering the JES through the Korea Strait (Takikawa and Yoon 2005) and in the integral transport measured by the underwater voltage cable between Nakhodka, Russia, and Naoetsu, Japan (Palshin et al. 2001). Further, Koldunov et al. (2007) found semiannual oscillation in JES surface height anomalies obtained from satellite altimetry data. The semiannual signal manifests itself in atmospheric variables on a broader spatial scale, particularly in sea level pressure. It was shown that the semiannual harmonic component is strong within the subtropical high pressure belts, especially over the northwest Pacific (Sedov 1990; Yashaev and Zveryaev 2001). However, the physical mechanisms of semiannual variability in the JES SST are not yet understood.

Dynamic processes are recognized as an important additional forcing of SST variability. These processes impose their signature on SST through turbulent entrainment at the base of the surface mixed layer. In particular, SST is affected by divergence of the surface layer caused by Ekman suction and heat advection by large-scale currents or by turbulent fluxes related to mesoscale dynamics. In recent decades, the JES has been intensively investigated in frame of international projects. Toba et al. (1984) was first to consider the Tsushima Current off Honshu, Japan, as a turbulent flow composed of mesoscale eddies. Currently, the old paradigm of permanent currents and persistent fronts has given way to the idea of the JES as a highly dynamic oceanic basin (see reviews by Chang et al. 2004; Danchenkov et al. 2006). Research has revealed that warm mesoscale eddies, often large stationary or moving systems with lifetimes of more than a year, can dominate instantaneous SST patterns (Sugimoto and Tameishi 1992; Isoda and Saitoh 1993; Danchenkov et al. 1997; Ginzburg et al. 1998; Park and Chung 1999; Lobanov et al. 2007; Nikitin 2007). More persistent contributions to SST can be also expected, but are not yet clarified in terms of large-scale modes of variability.

The frontal system of the JES is closely linked to mesoscale dynamics. The Subarctic Front can form several branches, as described by Nikitin (2007) (Fig. 12a). In particular, the northwestern (NW) branch of the Subarctic Front develops with the onset of the winter monsoon in October at the northeastern boundary of a cluster of warm eddies formed off North Korea (Danchenkov et al. 2006; Lobanov et al. 2007; Nikitin 2007). This front persists until early or late winter, separating warm and cold water. This is a regular seasonal phenomenon, but its signature has not yet been found in large-scale SST modes (Minobe et al. 2004; Park and Chu 2006).

The purpose of this study was to reveal SSTA related to dynamic processes in the JES. Modern products of daily SST with fine spatial resolution, such as the New Generation SST (NGSST) product for the Northwest Pacific (Tohoku University, Japan) and the Merged Satellite and In Situ Data Global Daily SST (MGDSST) product from the Japan Meteorological Agency (JMA), are presently available to perform this analysis. To reveal modes of SST variability and their characteristic spatial and temporal patterns, empirical orthogonal function (EOF) analysis was applied in a complex form that makes it possible to search for moving anomalies. To support our hypothesis on the impact of dynamic processes, linkages of SSTA to wind stress curl in the JES were examined. Numerical simulations with an oceanic model were performed to elucidate mechanisms responsible for these processes. The following topics are discussed: SST and wind data, typical patterns of wind stress and curl, and techniques for data analysis (Section 2); oceanic model and simulation setup (Section 3); comparison of modes of SST variability estimated from the NGSST and MGDSST data sets (Section 4); and the three leading modes of the SSTA, their links to wind stress curl, and responsible dynamic processes (Sections 5-7), followed by the conclusion (Section 8 ).

\section{Data and methods}

\section{SST data}

Two daily SST data sets with the fine spatial resolution were analyzed. NGSST is a regional product developed by Tohoku University, Japan, for the northwest Pacific (http://www.ocean.caos.tohoku.ac.jp/ merge/sstbinary/ actvalbm.cgi). Satellite infrared and microwave measurements were merged and binned into $0.05^{\circ}$ boxes. Data accuracy varies from 0.7 to $0.9^{\circ} \mathrm{C}$. Methods for data processing/merging and data set verification have been described by Guan and Kawamura (2004) and Hosoda and Kawamura (2004). We used the subset for the JES $\left(34.5^{\circ}-48^{\circ} \mathrm{N}, 127.5^{\circ}-142^{\circ} \mathrm{E}\right)$ for the period of 1 July 2002 to 7 July 2006 (about 1470 days). The Tatarsky Strait northward of $48^{\circ} \mathrm{N}$ and the East Korea Bay westward of $128.5^{\circ} \mathrm{E}$ were excluded because of frequent cloud cover and gaps between microwave swaths. The very few remaining gaps were filled in by linear interpolation performed individually for the binned time series. The data set was smoothed to $0.25^{\circ}$ boxes before EOF decomposition. 
Another SST data set used in this study was a subset of the MGDSST product. The MGDSST analysis has been in operation since April 2004. It is developed by the merging of satellite-observed infrared and microwave data with ship, float, and buoy observations and is subsequently binned into $0.25^{\circ}$ boxes (Sakurai et al. 2005). Data accuracy is within $1^{\circ} \mathrm{C}$. Daily SST data in the seas adjacent to Japan $\left(20^{\circ}-50^{\circ} \mathrm{N}, 120^{\circ}-160^{\circ} \mathrm{E}\right)$, an area rich in observations, are an extract of the MGDSST data set that extends back to the 1990s. We analyzed the data subset for the JES $\left(35^{\circ}-48^{\circ} \mathrm{N}, 127.5^{\circ}-42^{\circ} \mathrm{E}\right)$ for the period of 12 October 1993 to 8 November 2006 (about 4780 days). This subset is hereafter referred to as JMASST. Data were retrieved from the North-East Asian Regional (NEAR) Global Ocean Observing System (GOOS) Regional Delayed Mode Data Base (http://near-goos1. jodc.go.jp/).

\section{Wind data and typical patterns of wind stress and curl}

To analyze the relationship of SST with wind stress curl over the JES, we used ancillary data from the Seaviewing Wide Field-of-view Sensor (SeaWiFS) Project, a special National Centers for Environmental Prediction/ National Center for Atmospheric Research (NCEP/NCAR) product. These 6-h $1^{\circ}$-gridded surface zonal and meridional wind data for 1998-2005 are available on the Internet (ftp://oceans.gsfc.nasa.gov/METOZ/). The area covered $\left(34^{\circ}-53^{\circ} \mathrm{N}, 127^{\circ}-143^{\circ} \mathrm{E}\right)$ includes the JES and adjacent land masses. Wind stresses were computed using the bulk formulas, and wind curls at the $1^{\circ}$-box centers were computed by central differencing from the stresses at the corners. Intra-annual variation of wind stress curl over the JES is discussed in Section 6.

This data set was used to analyze wind variability over the JES (Trusenkova et al. 2007) by means of complex empirical orthogonal functions (CEOFs; for more details of this procedure, see a recent review of EOF analysis by Hannachi et al. 2007). Based on the leading CEOF mode, typical patterns of wind stress and curl were derived in such a way that they differed by the prevailing wind directions and curl spatial patterns (see Trusenkova et al. 2007, for details and comparisons with other studies on the JES winds). The original wind fields revealed synopticscale variability, while only persistent features remained in the typical patterns. The typical patterns for characteristic months are presented in Fig. 1 by arrows (stresses), contours (curls), and prevailing wind directions (thick arrows).
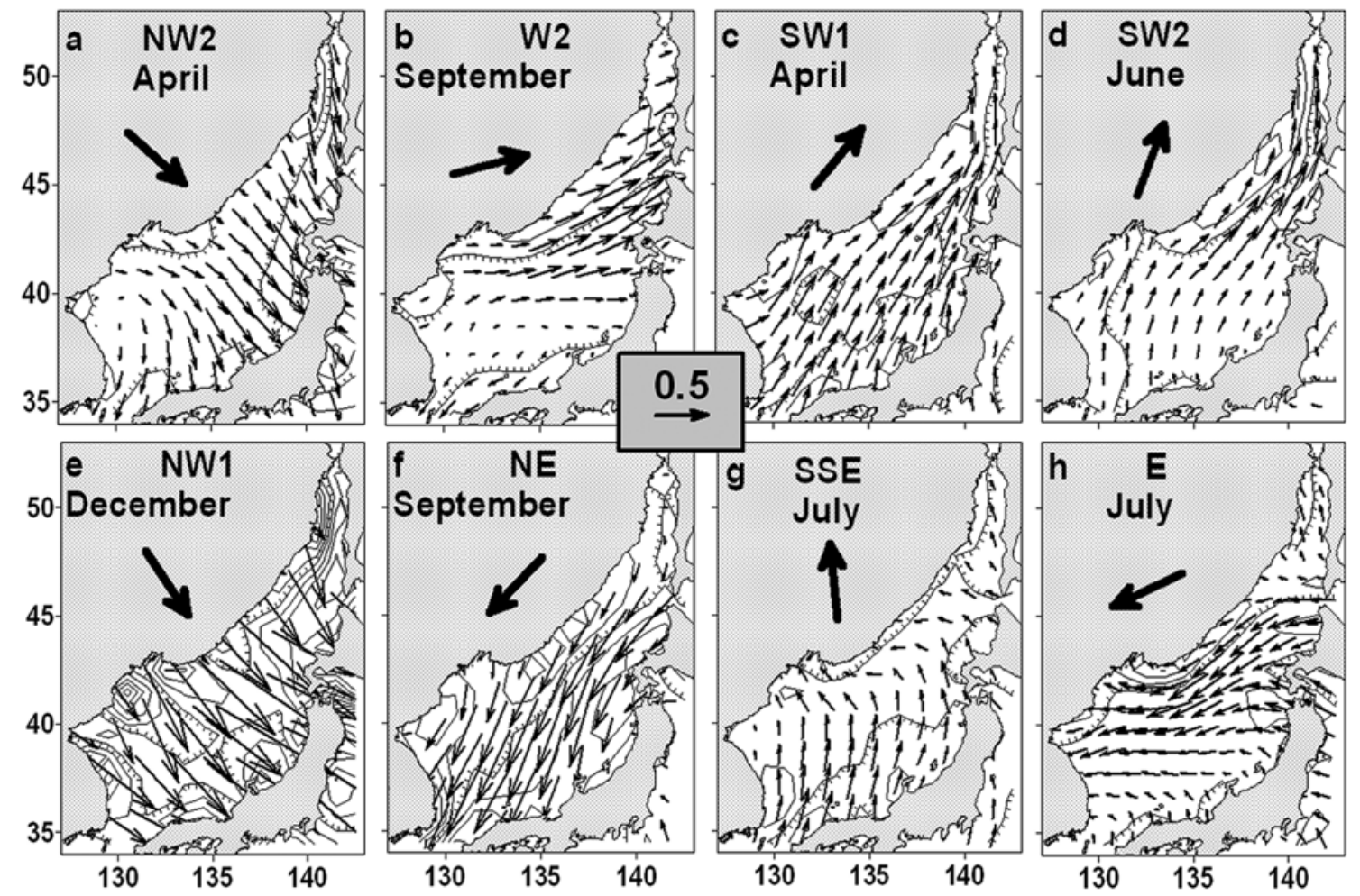

Fig. 1. Typical patterns of wind stress $\left(\mathrm{dyne} / \mathrm{cm}^{2}\right)$ and curl (contours every $\left.2 \times 10^{-8} \mathrm{dyne} / \mathrm{cm}^{3}\right)$ over the JES for characteristic months. The $\mathrm{C} / \mathrm{AC}$ curl is positive/negative; zero contour hatched downhill. Prevailing wind directions are shown as arrows. 
In relatively stable conditions of the winter monsoon, the northwestern (NW1) pattern prevails with a frequency of occurrence exceeding 50\% (Fig. 1e - December). This pattern features the cyclonic (C) curl over most of the JES with zones of the anticyclonic (AC) curl along the western and southeastern coasts. There is a curl dipole off Peter the Great Bay and a C curl belt off East Korea Bay. Two other frequent winter patterns are the northern $(\mathrm{N})$ and western (W1) patterns (not shown). The former, with an occurrence of about $20-30 \%$, reflects the intensified meridional wind component and the $\mathrm{AC}$ curl over the western JES. The latter, with an occurrence of about 10$20 \%$, is characterized by the intensified zonal wind component and the strong $\mathrm{C}$ curl over the entire JES.

In contrast, a variety of frequent, westerly (Fig. 1a-1d) and easterly (Fig. 1f-1h) patterns occurs in the warm season (Fig. 2). The southwestern (SW) pattern is most frequent in the early warm season (Fig. 2) and has two variations: the SW1 pattern in April, May, and July (Fig. 1c-April) and the SW2 pattern in June, August, and September (Fig. 1d - June). The NW2 (Fig. 1a - April) and W2 (Fig. 1b - September) patterns differ from their winter counterparts NW1 (Fig. 1e) and W1 (not shown) by the prevalence of the AC curl. As a whole, the westerlies feature frequent $\mathrm{AC}$ curl over the eastern (NW2, W2, SW1, and SW2 patterns) and central (NW2, W2, and SW2 patterns) JES, the C-curl over the western JES (SW pattern), and a dipole-shaped curl over the northernmost JES (W2, SW1, and SW2 patterns).

The easterly-northeastern (NE; Fig. 1f - September), south-southeastern (SSE; Fig. $1 \mathrm{~g}$ - July), and eastern (E; Fig. 1h - July) patterns feature the $\mathrm{C}$ curl over the eastern and central JES, a zone of the AC curl along the western coast, and a weak AC curl northward of $46^{\circ} \mathrm{N}$. These patterns become more frequent by late summer (Fig. 2). A general tendency of the opposite curl southward and northward of $44-46^{\circ} \mathrm{N}$ manifests itself in the summer patterns, i.e., the $\mathrm{C}(\mathrm{AC})$ curl is more frequent in the

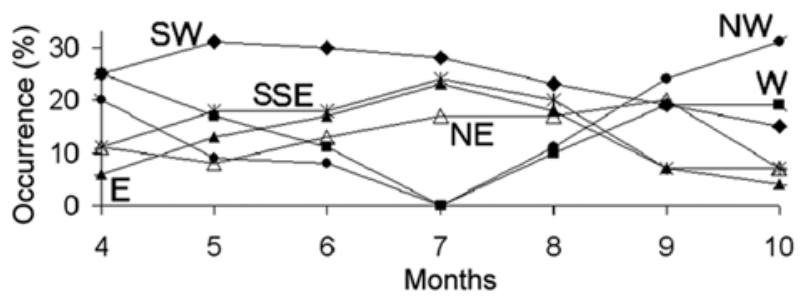

Fig. 2. Monthly frequency of occurrence of the NW (circles), W (squares), SW (diamonds), SSE (asterisks), E (filled triangles), and NE (open triangles) patterns from April through October. southern (northern) JES in the easterly patterns and vice versa in the westerly patterns (Fig. 1). These typical patterns were applied as wind forcing in the simulations discussed in Section 3.

\section{Techniques of data analysis}

CEOF analysis is useful for identifying standing and moving anomalies in scalar fields (Hannachi et al. 2007). The CEOF techniques in the time domain is a straightforward extension of the conventional EOF method with similar mathematical formulation, but in a complex form. This yields the well-known decomposition of a signal $X(r, t)$ into spatial and temporal components sorted by decreasing variance:

$$
\mathrm{X}(\mathbf{r}, \mathrm{t})=\sum \mathrm{A}_{\mathrm{k}}^{*}(\mathbf{r}) \mathrm{B}_{\mathrm{k}}(\mathrm{t}),
$$

where $\mathrm{X}(\mathbf{r}, \mathrm{t})=\mathrm{X}_{\mathrm{r}}(\mathbf{r}, \mathrm{t})+\mathrm{iX}(\mathbf{r}, \mathrm{t})$ is the complex signal, the real part $X_{r}(r, t)$ is the original scalar field (SST), the imaginary part- $X_{i}(r, t)$ is the Hilbert transform of $X_{r}(r, t)$, $r$ denotes spatial coordinates, and $t$ is time. The complex signal contains information on the time lags, thus allowing for the detection of moving anomalies. The asterisk denotes the complex conjugate, and $\mathrm{k}$ is the mode number. $A_{k}(r)$ represent basic orthogonal functions (i.e., CEOFs). In this case, they are identified as eigenvectors derived from the correlation matrix rather than from more common covariances (Hannachi et al. 2007). However, correlation-like measures are widely used in other multivariate techniques of data analysis. The root-meansquare pre-normalization of the signal $X(\mathbf{r}, \mathrm{t})$ provided by correlations facilitates identification of low-amplitude SSTA in the northern JES. $B_{k}(t)$ is a temporal coefficient or principal component (PC). Complex CEOFs and PCs can be represented as

$$
\mathrm{A}_{\mathrm{k}}(\mathbf{r})=A_{\mathrm{k}}(\mathrm{r}) \mathrm{e}^{-\mathrm{i} \varphi} \text { and } \mathrm{B}_{\mathrm{k}}(\mathrm{t})=B_{\mathrm{k}}(\mathrm{t}) \mathrm{e}^{-\mathrm{i} \phi} \text {, respectively, }
$$

where $A_{\mathrm{k}} / B_{\mathrm{k}}$ are spatial/temporal amplitude and $\varphi_{\mathrm{k}} / \phi_{\mathrm{k}}$ are spatial/temporal phase. The phase is defined as $-180^{\circ}(-\pi)$ to $180^{\circ}(\pi)$.

In the case of a standing SSTA, seesaw $\left(180^{\circ}\right.$ out-ofphase) areas are separated by $180^{\circ}$ jumps of spatial phase, while the SSTA moves along the path of gradually increasing spatial phase when the temporal phase progressively increases. The phase speed $\mathrm{v}$ can be estimated as

$$
\mathrm{v} \approx \omega / \mathrm{k} \approx(2 \pi / \mathrm{T}) /(\Delta \theta / \mathrm{L})
$$

where $\omega=2 \pi / T, k=\Delta \theta / L, T$ refers to a characteristic period of the temporal phase, and $\Delta \theta$ is a spatial phase increment corresponding to the path of length $\mathrm{L}$. 
To represent temporal behavior of the $\mathrm{k}^{\text {th }}$ mode, a characteristic time series related to the $\mathrm{k}^{\text {th }}$ mode can be defined as follows:

$$
X_{r}^{(k)}(t)=A_{k}\left(r_{0}\right) B_{k}(t)
$$

where $\mathbf{r}_{\mathbf{0}}$ is a characteristic location usually within a local amplitude maximum, and $\mathrm{X}_{\mathrm{r}}^{(\mathrm{k})}$ has the dimension of the original data $\left({ }^{\circ} \mathrm{C}\right.$ for SST). Accordingly, an instantaneous SSTA pattern related to the $\mathrm{k}^{\text {th }}$ mode can be represented by $X_{t}^{(k)}(r)=A_{k}(r) B_{k}\left(t_{0}\right)$ for time $t_{0}$.

The seasonal signal is strongest in SST and should be removed before analyzing anomalies. The usual method for monthly data sets is to subtract long-term monthly means; however, the 4-year duration of NGSST was not sufficient for this estimation. Moreover, removing monthly or daily 13-year means from JMASST did not yield interpretable patterns. Instead, we calculated the seasonal signal as the leading mode of the original SST (Section 4). Anomalies can be defined as follows:

$$
X_{a}^{(1)}(\mathbf{r}, t)=X(r, t)-A_{1}(r) B_{1}(t)
$$

$\mathrm{X}_{\mathrm{a}}{ }^{(1)}$ is hereafter referred to as the first-order residual anomaly. This procedure can be repeated by subtracting the leading mode from $\mathrm{X}_{\mathrm{a}}^{(1)}$ and, thus, obtaining the second-order residual anomalies and so on, with the only limitation being maintaining a sufficient variance in the data. Higher order anomalies can be useful for revising the stability of patterns.

To check the statistical significance of CEOFs, errors in the corresponding eingenvalues were estimated as described by North et al. (1982):

$$
\Delta \lambda_{\mathrm{k}}=\lambda_{\mathrm{k}}\left(2 / \mathrm{N}_{\mathrm{k}}^{*}\right)^{1 / 2}
$$

where $\lambda_{\mathrm{k}}$ is the eigenvalue corresponding to the $\mathrm{k}^{\text {th }}$ mode, $\Delta \lambda_{\mathrm{k}}$ is its error, and $\mathrm{N}_{\mathrm{k}}^{*}$ is the number of degrees of freedom. The latter is estimated for the time series related to the $\mathrm{k}^{\text {th }}$ mode (Eq. (3)), considering autocorrelation, and averaged within the amplitude maxima. Eigenvalues can be expressed as fractions of the total variance, $\mu_{\mathrm{k}}=\lambda_{\mathrm{k}} /$ $\Sigma \lambda_{\mathrm{k}}$, and their errors are converted to $\Delta \mu_{\mathrm{k}}=\mu_{\mathrm{k}}\left(2 / \mathrm{N}_{\mathrm{k}}{ }^{1 / 2}\right.$. The $95 \%$ confidence interval is given by $\mu_{\mathrm{k}} \pm \Delta \mu_{\mathrm{k}}$, and a threshold of statistical significance can be defined as

$$
\mathrm{T}_{\mathrm{k}}=\left(\mu_{\mathrm{k}}-\mu_{\mathrm{k}+1}\right) /\left(\Delta \mu_{\mathrm{k}}+\Delta \mu_{\mathrm{k}+1}\right)
$$

if the eigenvalues are sorted by the decreasing variance. An eigenvalue is considered non-degenerate if $T>1$. In this case, the corresponding eigenvector can be reliably estimated (Quadrelli et al. 2005). Decompositions of the original fields and their first- and second-order anomalies for NGSST and JMASST were performed. Table 1 presents the criteria for the statistical significance of the leading modes.

To estimate dominant variability time scales, wavelet analysis was applied. This method is designed for the

\begin{tabular}{|c|c|c|c|c|c|c|c|c|c|c|}
\hline \multicolumn{6}{|c|}{ NG SST } & \multicolumn{5}{|c|}{ JMA SST } \\
\hline Mode No. & $\mathbf{N}^{*}$ & $\mu$ & $\Delta \mu$ & $\mathbf{T}$ & $\begin{array}{c}\text { Statistical } \\
\text { significance }\end{array}$ & $\mathbf{N}^{*}$ & $\mu$ & $\Delta \mu$ & $\mathbf{T}$ & $\begin{array}{c}\text { Statistical } \\
\text { significance }\end{array}$ \\
\hline \multicolumn{11}{|c|}{ Original SST } \\
\hline 1 & 170 & 96.18 & 10.43 & 9.05 & Yes & 571 & 96.10 & 5.69 & 16.53 & Yes \\
\hline 2 & 177 & 0.89 & 0.09 & 1.88 & Yes & 593 & 1.05 & 0.06 & 4.97 & Yes \\
\hline 3 & 172 & 0.59 & 0.06 & 2.77 & Yes & 578 & 0.58 & 0.03 & 7.41 & Yes \\
\hline 4 & 151 & 0.31 & 0.04 & 2.08 & Yes & 584 & 0.23 & 0.01 & 3.25 & Yes \\
\hline 5 & 152 & 0.19 & 0.02 & & & 579 & 0.15 & 0.01 & & \\
\hline \multicolumn{11}{|c|}{ SSTA1 } \\
\hline 1 & 175 & 32.02 & 3.42 & 2.73 & Yes & 191 & 36.47 & 3.73 & 3.53 & Yes \\
\hline 2 & 102 & 16.41 & 2.30 & 2.57 & Yes & 182 & 17.02 & 1.78 & 4.41 & Yes \\
\hline 3 & 142 & 8.04 & 0.95 & 2.49 & Yes & 178 & 6.24 & 0.66 & 2.54 & Yes \\
\hline 4 & 141 & 4.37 & 0.52 & & & 179 & 3.59 & 0.38 & & \\
\hline \multicolumn{11}{|c|}{ SSTA2 } \\
\hline 1 & 110 & 19.94 & 2.69 & 1.70 & Yes & 188 & 21.60 & 2.23 & 3.10 & Yes \\
\hline 2 & 111 & 12.52 & 1.68 & 2.53 & Yes & 184 & 11.10 & 1.16 & 2.76 & Yes \\
\hline 3 & 109 & 6.16 & 0.83 & & & 182 & 6.13 & 0.64 & & \\
\hline
\end{tabular}

Table 1. Statistical significance of the leading SST modes. $\mathrm{N}^{*}$ is the number of degrees of freedom, $\mu$ is the fraction (\%) of the total variance accounted for by the corresponding mode, $\Delta \mu$ is its error, and $T$ is the threshold of statistical significance by Eq. (6) 
estimation of time-varying periodicities. A guide to wavelet analysis and software has been provided by Torrence and Compo (1998). The Morlet function, adapted for capturing periodicities, was used as a basic mother wavelet. The smallest period (scale) of 40 days was chosen to filter out small-scale noise for wavelet reconstruction (filtering) of the time series (see Section 6). Cross-wavelet spectra and band-pass-filtered time series were computed to analyze the joint variability of SST and wind. Global wavelet spectra providing unbiased estimates of the true power spectra (Torrence and Compo 1998) were estimated by time averaging local spectra. Results were considered reliable within the cone of influence (COI) outlining the region, where the edge effects can be neglected, and for the wavelet power above the $95 \%$ significance level. The latter was estimated from the theoretical red noise spectrum that was assumed as the null hypothesis (Torrence and Compo 1998).

\section{Oceanic model and simulation setup}

\section{Model description}

Numerical simulations were performed using a quasiisopycnic model (Mikhaylova and Shapiro 1993; Shapiro 2000) that was applied to the JES, as discussed in detail by Trusenkova and Ishida (2005). In this model, the surface mixed layer and internal layers were introduced in the vertical. Variable density was postulated for any layer; its variations were unlimited in the surface layer but were constrained in the internal layers by a "base density." If the density in a layer was out of its base limits, the layer would outcrop (i.e., physically disappear), and the water would move to an adjacent layer of an appropriate base density. The base density sets up the vertical resolution and can be attributed to interfaces between layers. It increases from zero at the interface of the first and second layers to very (infinitely) high at the base of the bottom layer.

The model is represented by a set of 2-D prognostic momentum, temperature, salinity, continuity, and state equations formulated at the beta plane under the hydrostatic and Boussinesq approximations for every layer. These were derived by integration of original primitive equations in the vertical within layers. The free surface was retained. Bi-harmonic viscosity was applied in the momentum equations. Closure for the surface mixed layer was provided by the turbulent kinetic energy equation so that both its depth and entrainment rate at the base could be determined. Cyclic regimes were supported, particularly the seasonal variation of the mixed layer depth under seasonally varying forcing of surface buoyancy (heat and freshwater) fluxes and wind. Surface fluxes were calculated using atmospheric variables and water temperature in the surface model layer. Restoration conditions towards observed temperature or salinity were not applied.

Ice models were not included; surface fluxes were set equal to zero if the surface water reached the freezing point. This is acceptable because ice cover is very limited in the JES. In the internal layers, either layer thickness or entrainment rate can be estimated from the continuity equation. If positive thickness is possible, the entrainment rate is set equal to zero; otherwise, a layer outcrops and acquires a zero thickness with entrainment at its base. In the case of vertical instability, including winter convection, the convective adjustment procedure was applied. Note that variable density facilitates coupling of the surface mixed and internal layers and prognostic temperature and salinity.

\section{Simulation setup}

Model geometry and bottom topography along with

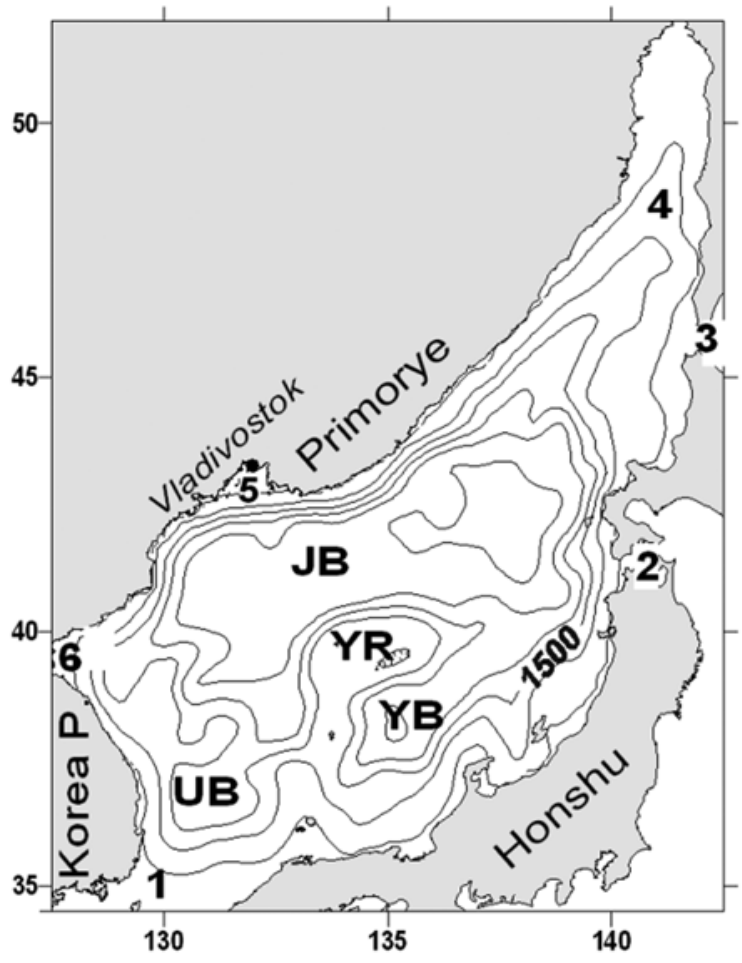

Fig. 3. The scaled bathymetry (m) applied in the model with contours every $500 \mathrm{~m}$. Regions are labeled as follows: Korea Strait (1), Tsugaru Strait (2), La Perouse (Soya) Strait (3), Tatarsky (Mamiya) Strait (4), Peter the Great Bay (5), East Korea Bay (6), Japan Basin (JB), Yamato Rise (YR), Yamato Basin (YB), and Ulleung Basin (UB). 
some regional and bathymetric features are shown in Fig. 3. Bathymetry was adopted from navigation maps. To diminish topographic slopes, the sea depth was scaled by a factor of 0.75 in such a way that the average depth remained unchanged, and minimum (maximum) depth was approximately $400 \mathrm{~m}(3100 \mathrm{~m})$. The depth was further smoothed by a nine-point filter. A $1 / 8^{\circ}$ mesh and 12 layers in the vertical were accepted. The isopycnic bi-harmonic viscosity and harmonic diffusivity were made equal to $2.5 \times 10^{8} \mathrm{~m}^{4} / \mathrm{s}$ and $250 \mathrm{~m}^{2} / \mathrm{s}$, respectively. The baroclinic Rossby radius of deformation was about $25 \mathrm{~km}$ in the southern JES and about $10 \mathrm{~km}$ in the northern JES during the summer season. The small Rossby radius can be explained by the thin thermocline of 50-60 (400-500) $\mathrm{m}$ in the northern (southern) JES. Considering the spatial resolution and viscosity/diffusivity, the simulation setup was only marginally eddy-resolving.

The major inflow port is the Korea Strait, with transport seasonally varying between its minimum of $1 \times 10^{6} \mathrm{~m}^{3} / \mathrm{s}$ in February and maximum of $2 \times 10^{6} \mathrm{~m}^{3} / \mathrm{s}$ in October, as described by Leonov (1960). These values are lower than the recently reported range of $2-3 \times 10^{6} \mathrm{~m}^{3} / \mathrm{s}$ (Takikawa and Yoon 2005). The purpose of selecting smaller transport related to the mid-20th century was to avoid possible overshooting of the East Korea Warm Current (EKWC), which could develop in the simulations with only marginal resolution of mesoscale dynamics. An important source of fresh water, despite its low transport $\left(\sim 10^{3} \mathrm{~m}^{3} / \mathrm{s}\right)$, is the Amur River Estuary at the northern border of the Tatarsky (Mamiya) Strait in winter/spring; fresh water is also supplied from other rivers and runoff from coastal areas. The outflow ports are the Tsugaru and La Perouse (Soya) Straits, which divide transport in a ratio of $7: 3$.

At the initial state of rest, flat interfaces between the layers were set up at 10, 25, 50, 75, 100, 150, 250, 350, 500,700 , and $900 \mathrm{~m}$; the temperature/salinity of the layers and the base buoyancy were taken from average vertical profiles. The numerical model was spun up with a time step of $7.5 \mathrm{~min}$ for 10 years under the forcing of NCEP monthly wind stresses for 2000 . Surface buoyancy forcing was mostly from monthly NCEP fields for the last decades of the 20th century, with the exception of precipitation, which was taken from the Global Precipitation Climatology Project (GPCP) data set for 1979-2001. The external monthly fields were timed at mid-months with linear interpolation at every time step.

Following the spin-up, three model runs were performed for 2 years under the forcing of typical wind patterns, as discussed in Section 2. Surface buoyancy forcing and transports in the straits remained the same for the three runs; thus, the response of the JES circulation can be attributed to the change of the wind stress curl. As the curl is mostly cyclonic over the JES in winter, the runs differed by summer curl. From October through March, the most frequent NW1 wind pattern (Fig. 1e) was applied in all cases. From April through September, the forcing of an alternating C/AC curl was applied in Run 1, a moderate $\mathrm{C}$ curl was applied in Run 2, and a strong $\mathrm{C}$ curl was applied in Run 3. The SW patterns were applied in May-August, and the W patterns were applied in April and September for Run 1. The SSE patterns were applied in April-September for Run 2. In Run 3, the E patterns were applied in April-August and the NE patterns were applied in April and September for the transition between winter and summer (Table 2). Results from the last year of integrations are discussed.

\section{Seasonal signal and residual anomalies of NGSST and JMASST}

The leading mode of the original SST accounted for about $96 \%$ of the total variance for both the NGSST and JMASST data sets. The criterion for statistical significance of the corresponding eigenvalues (Eqs. (5) and (6)) was satisfied (North et al. 1982) (Table 1). The spatial and temporal patterns were practically identical in both cases. This mode was highly spatially homogeneous with an amplitude variation of less than $4 \%$ and a constant phase (Fig. 4a, 4b-JMASST). Characteristic time series related to Mode 1 for NGSST (red line) and JMASST (blue line) were computed by Eq. (3) in the location represented by an asterisk (Fig. 4a). As shown in Fig. 5, they completely overlapped for the joint period from July 2002 and revealed maxima in August and minima in FebruaryMarch. They also showed that spring warming occurs

Table 2. Typical wind patterns applied for forcing runs 1-3

\begin{tabular}{lllllllllllll}
\hline & Jan. & Feb. & March & April & May & June & July & Aug. & Sept. & Oct. & Nov. & Dec. \\
\hline Run 1 & NW & NW & NW & W & SW & SW & SW & SW & W & NW & NW & NW \\
Run 2 & NW & NW & NW & SSE & SSE & SSE & SSE & SSE & NE & NW & NW & NW \\
Run 3 & NW & NW & NW & NE & E & E & E & E & NE & NW & NW & NW \\
\hline
\end{tabular}


faster than autumn cooling and revealed interannual variability in the annual cycles. Therefore, this mode can

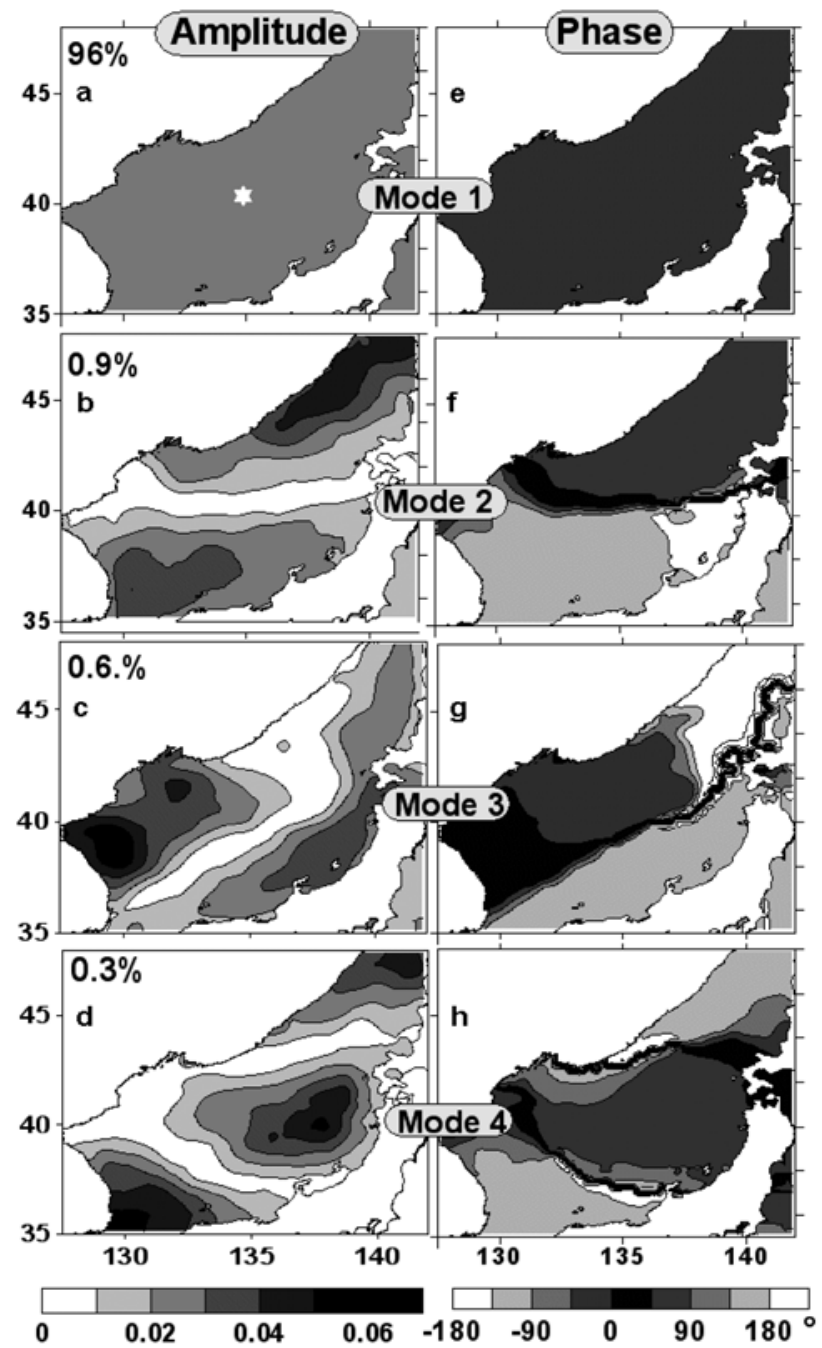

Fig. 4. Spatial amplitude (a-d) and phase ( $\left.{ }^{\circ}\right)$ (e-h) of modes 1-4 for the original JMASST. An asterisk shows the location of the characteristic time series in Fig. 5. be considered as a spatially averaged seasonal signal in the JES SST.

The fraction of the total variance accounted for by the seasonal signal (about $96 \%$ in both cases) may seem exaggerated. However, Park et al. (2005) reported that the 12-month harmonic component accounts for $88-96 \%$ of the total SST variance, depending on the location. The characteristic time series related to Mode 1 differed from the ideal sinusoid because the annual cycles were asymmetric and had interannual variability (Fig. 5). For this reason, the fraction of variance accounted for by Mode 1 reached an upper limit of that found by Park et al. (2005).

First-order residual anomalies (SSTA1) were computed for the NGSST and JMASST data sets by removing the seasonal signal, defined as the contribution of Mode 1, from the original SST using Eq. (4). The criterion (Eqs. (5) and (6)) for statistical significance of the corresponding eigenvalues (North et al. 1982) held for modes 1-3 in both cases (Table 1). Spatial patterns for modes 1-3 are presented in Fig. 6, and characteristic time series related to modes 1-3 (Eq. (3)) for the NGSST and JMASST data sets (asterisks in Fig. 6) are presented in Fig. 7 for the common period from July 2002. The former are shown by dashed lines and the latter by solid lines. The statistical significance (Table 1) and coherent spatial and temporal patterns of modes 1-3 from both the NG and JMA data sets (Fig. 6, 7) justified their consideration despite the small fraction (4\%) of the total variance of the original SST accounted for by anomalies.

Modes 1 and 2 had practically identical spatial patterns for the NGSST and JMASST data sets, showing bi-core seesaw patterns with $180^{\circ}$ phase difference between cores (Mode 1 - Fig. 6a, 6d, Fig. 6g, 6j; Mode 2 - Fig. 6b, 6e, Fig. 6h, 6k). Mode 3 had similar although not identical spatial patterns in both cases. This mode featured in-

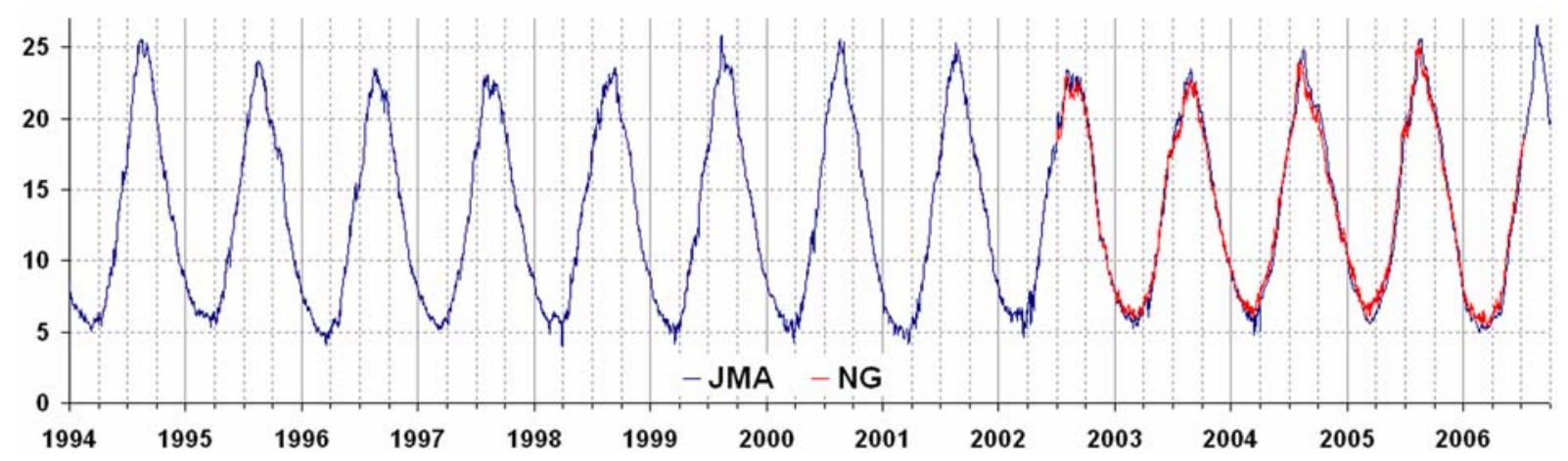

Fig. 5. Average seasonal signal in the JES SST. Characteristic time series $\left({ }^{\circ} \mathrm{C}\right)$ related to Mode 1 of the original NG (red line) and JMA (blue line) SST at the location shown by the asterisk in Fig. 4 a. 

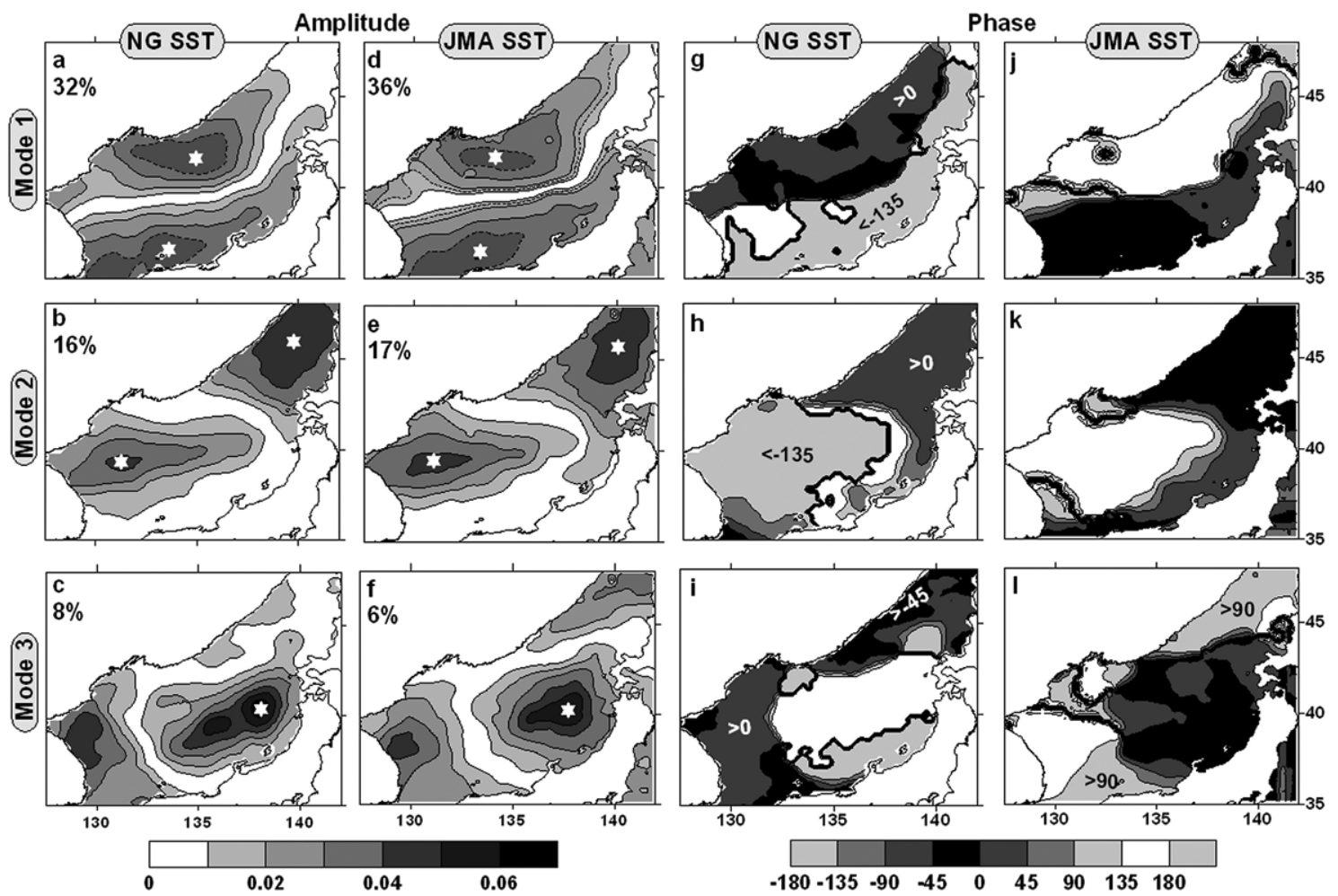

Fig. 6. Spatial amplitude (a-f) and phase $\left({ }^{\circ}\right)$ (g-l) of modes 1-3 for NG (a-c, g-i) and JMA (d-f, j-l) SSTA1. Additional amplitude contours are dashed $(a, d)$. Asterisks show locations of characteristic time series (a-f).

phase western and northern cores and an out-of-phase eastern core (NGSST - Fig. 6c, 6f; JMASST - Fig. 6i, 61). The characteristic time series for the NGSST and JMASST data sets revealed, on average, only a slight bias of less than $0.5^{\circ} \mathrm{C}$ for Mode 1 (Fig. 7a) and between $0.5^{\circ} \mathrm{C}$ and $1^{\circ} \mathrm{C}$ for Mode 2 (Fig. 7b). Bias for Mode 3 was larger and often comparable with the SSTA magnitude (Fig. 7c). SSTA weakened from Mode 1 to Mode 3 (Fig. 7). Modes 2 and 3 of the original SST had bi-core seesaw patterns (Fig. 4), but there was no exact match to modes 1 and 2 of SSTA1. The spatial patterns changed after removing the dominant seasonal signal. In contrast, Mode 4 of the original SST and Mode 3 of SSTA1 resembled each other (JMASST-Fig. 4d, 4h; Fig. 6i, 61).

The instantaneous original NGSST and JMASST fields had some differences in magnitude and local spatial structures, but the three leading modes of SSTA were similar. This means that both data sets captured major variability features and justified JMASST analyses extending back to the pre-microwave period when there were frequent gaps in observations. The 13-year duration of the JMASST allowed us to reliably estimate dominant time scales by application of wavelet analysis (Section 2) to the characteristic time series in the southern core of
Mode 1 (Fig. 8a), western core of Mode 2 (Fig. 8d), and eastern (Honshu) core of Mode 3 (Fig. 8g). The corresponding local wavelet spectra are shown in Fig. $8 \mathrm{~b}, 8 \mathrm{e}$, and $8 \mathrm{~h}$, respectively, and the global (time-averaged) spectra are shown in Fig. 8c, 8f, and 8i, respectively. The 95\% significance level and COI are shown by red contours (Fig. 8).

The spectral power for Mode 1 was concentrated near the 12-month period with maximum values in 1998-2000 (Fig. 8b, 8c). The global wavelet spectrum for Mode 2 had statistically significant maxima for the periods of 0.5 , 1.0, 2.2, and 3.1 years (Fig. 8f). The local spectrum showed that the semiannual oscillation was statistically significant most of the time (Fig. 8e). The 12-month oscillation amplified and reached the statistically significant level only when the semiannual oscillation weakened. Quasi-biennial oscillation was statistically significant within the COI; its time scale shifted from 2.2 to 2.75 years in 2002 (Fig. 8e). As expected, the changing time scale was poorly represented in the global spectrum. The local power for Mode 3 revealed the 12-month oscillation that was statistically significant within the COI (Fig. 8h) and in the global spectrum (Fig. 8i). The global spectrum showed the 2.5-year statistically significant maximum, 


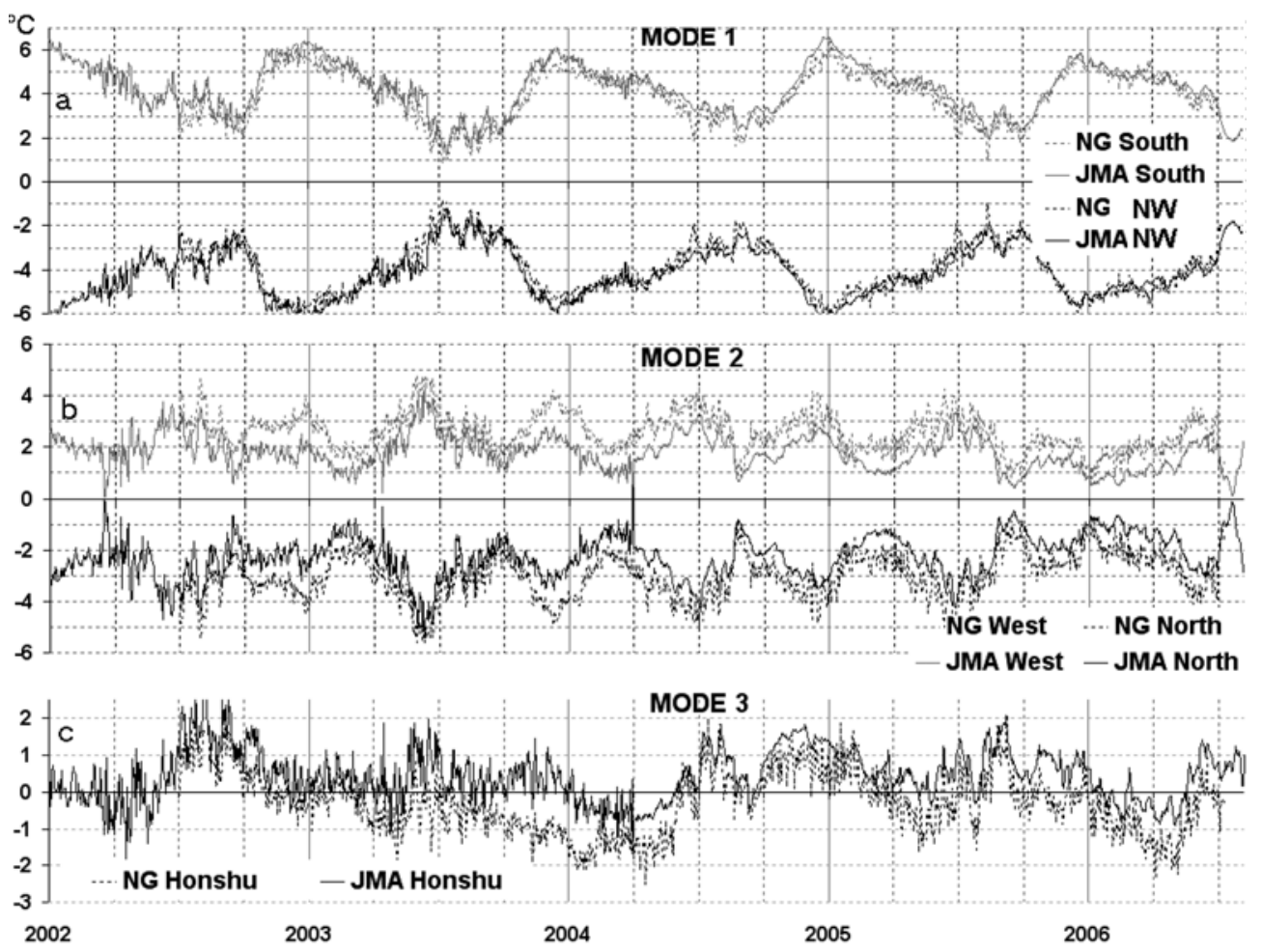

Fig. 7. Characteristic time series $\left({ }^{\circ} \mathrm{C}\right)$ related to modes 1-3 for NG (dotted lines) and JMA (solid lines) SSTA1 at the locations shown in Fig. 6.

while the local spectrum revealed that the time scale shifted from 2.8 to 2.1 years in 2001-2002. In this study, only 6- and 12-month time scales are discussed. Analysis of the quasi-biennial signal requires special consideration.

\section{Adjustment to the average seasonal signal}

Mode 1 of SSTA1 showed a seesaw pattern between the southern and NW areas (hereafter Southern Core and NW Core; NGSST-Fig. 6a, 6g; JMASST-Fig. 6d, 6j), with positive and negative contributions to SST, respectively (Fig. 7a). This allowed us to consider it as an addition (adjustment) to the average seasonal signal (Section 4), with the largest contribution of $6-7^{\circ} \mathrm{C}$ in late December and the smallest of $2^{\circ} \mathrm{C}$ in July and August (Fig. 8a for the Southern Core. Note that the characteristic time series in the NW Core is $\mathrm{x}$-axis mirrored). This contribution resulted in a higher amplitude of the annual cycle and earlier seasonal minimum in the northern JES, compared to the southern region, in line with the finding of Park et al. (2005). Therefore, Mode 1 is hereafter referred to as the Adjustment Mode. The 0.035-0.03 amplitude contours in the Southern Core outline an area of warm water entering the JES through the Korea Strait
(Fig. 6a, 6d). Note that the transport in the Korea Strait is largest in October-November (Takikawa and Yoon 2005), and SSTA related to the Adjustment Mode reached its maximum in late December (Fig. 8a).

The amplitude in the NW Core (Fig. 6a, 6d) was highest in the area of $\mathrm{C}$ wind stress curl southeastward of Peter the Great Bay (Fig. 3), typical of the winter NW (Fig. 1e) and $\mathrm{N}$ (not shown) wind patterns. This is the part of the curl dipole on the eastern and western sides of the wind jet off Vladivostok, which is caused by the adjacent land orography (Kawamura and Wu 1998). The spatial amplitude of the Adjustment Mode was decreased southwestward of Peter the Great Bay in the area of AC wind stress curl. The amplitude was increased in East Korea Bay (Fig. 6a, 6b), where the curl was cyclonic in the NW wind pattern (Fig. 1e). In contrast, wind speed (not shown) was largest at the jet axis off Peter the Great Bay and in the northeastern JES off the Tsugaru Strait, away from the highest amplitude of the Adjustment Mode. The 0.02 and 0.03 amplitude contours stretching off the North Korea coast (Fig. 6a, 6d) ran along the NW branch of Subarctic Front (Section 1) as shown in Fig. 12a (Nikitin 2007). The NW front developed with the onset of the winter monsoon, usually in mid-October, and 

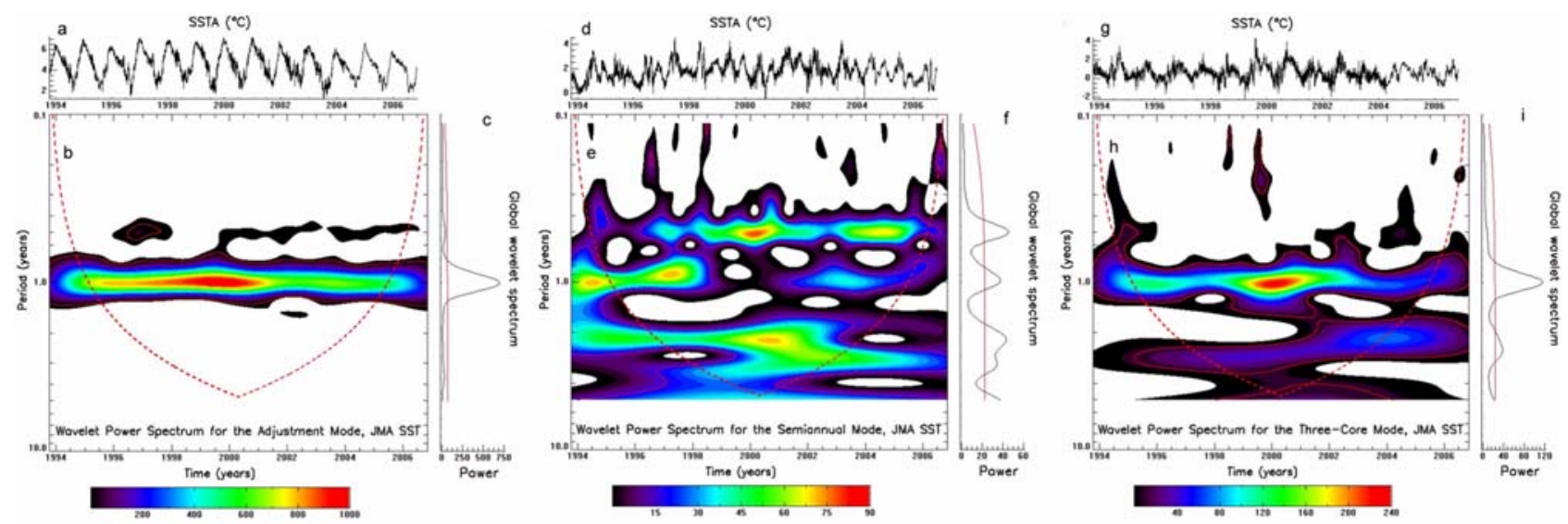

Fig. 8. Dominant time scales of modes 1-3 for JMA SSTA1. (a) Characteristic time series $\left({ }^{\circ} \mathrm{C}\right)$ in the Southern Core of the Adjustment Mode and its (b) local and (c) global wavelet power spectra $\left({ }^{\circ} \mathrm{C}^{2}\right)$. (d-f) Same as previous, except for the Western Core of the Semiannual Mode. (g-i) Same as previous, except for the Honshu Core of the Three-Core Mode. Local wavelet power is shown in white for values less than $40^{\circ} \mathrm{C}^{2}$ in (a) and less than $5^{\circ} \mathrm{C}^{2}$ in (e) and (h). The $\mathrm{COI}$ is shown as red dashed contours. The $95 \%$ significance level estimated from the theoretical red noise spectrum is shown as solid red contours.
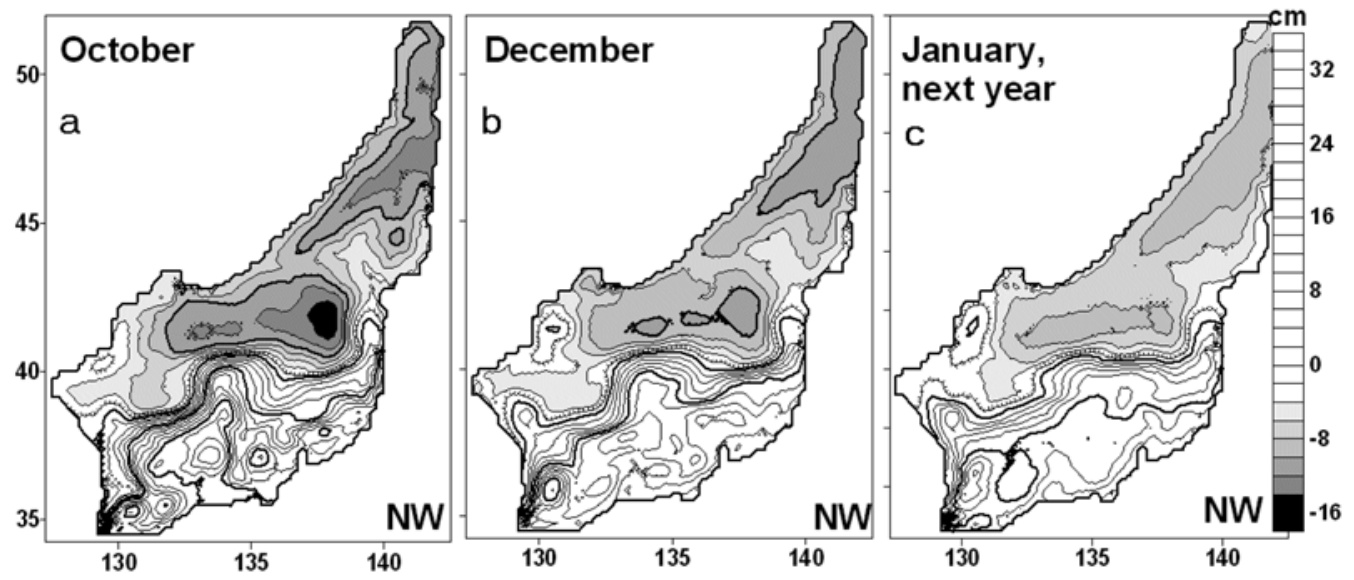

Fig. 9. Sea surface height $(\mathrm{cm})$ simulated under forcing of the NW wind pattern for (a) October, (b) December, and (c) January (next year). Contours of $0,10,20$, and $30 \mathrm{~cm}$ are shown in thick lines. Hatches downhill.

persisted until December or, in some years, late winter, while the Adjustment Mode reached its extremum in late December (Fig. 7a).

Wind stress curl can force SST through the divergence in the surface layer and upward displacement of isopycnals caused by Ekman suction. In winter, the thinner mixed layer cools faster. The JES circulation simulated under the forcing of the NW wind pattern is represented by sea surface height (SSH) in October, December, and January of the next year (Fig. 9). The C gyre revealed by $\mathrm{SSH}$ depression was located in the Japan Basin eastward of $131-132^{\circ} \mathrm{E}$, while a local AC gyre revealed by SSH rise developed off North Korea. The boundary between them corresponded to the observed NW branch of the Subarctic Front (Fig. 12a). The $\mathrm{C}$ circulation was simulated in East Korea Bay (Fig. 9). Similar features were simulated under the forcing of NCEP/NCAR monthly winds 2000 (Trusenkova and Ishida 2005) and European Center for Mid-Range Weather Forecast (ECMWF) climatological winds by Yoon et al. (2005).

Negative (positive) SSTA in the northwestern (southern) JES can be explained by the differential cooling in winter. However, an additional dynamic forcing by wind stress curl had an impact on SSTA in the NW region. The Southern and NW cores were affected by different dynamic processes, but were combined in the same mode due to similar temporal variability. 


\section{Semiannual mode}

\section{Relationship of the Semiannual Mode with wind stress curl}

Mode 2 represents a seesaw between the western and northernmost (northward of $42^{\circ}-43^{\circ} \mathrm{N}$ ) JES (NGSST-Fig. 6b, 6h; JMASST-Fig. 6e, 6k), oscillating on the dominant semiannual and quasi-biennial time-scales (Fig. 8d-8f). This mode is hereafter referred to as the Semiannual Mode. Its contribution to SST was positive in the Western Core and negative in the Northern Core (Fig. 7b). It reached $3-4.5^{\circ} \mathrm{C}$ in May/June and $2-3.5^{\circ} \mathrm{C}$ in November/ December. It fell below $1{ }^{\circ} \mathrm{C}$ in February/March and in August/September. Maxima were stronger in spring than in autumn, contributing to the weaker 12-month oscillation (Fig. 8e, 8f). To check for pattern stability, the secondorder residual SSTA (SSTA2) was computed using Eq. (4), so that the signal of the Adjustment Mode was removed. Modes 1 and 2 of SSTA 2 can be considered statistically significant for both the NGSST and JMASST data sets, as the corresponding eigenvalues satisfy North et al.'s (1982) criterion (Table 1). The spatial pattern of the Semiannual Mode changed only slightly from SSTA1 to SSTA2 with the northeastward expansion of the Western Core (NGSST-Fig. 15a; JMASST-Fig. 12a). The characteristic time series for both NG and JMA SSTA2 (not shown) were closely correlated, by a coefficient of 0.99 , to their counterparts from SSTA1, although the anomaly magnitude was decreased by $0.2-0.5^{\circ} \mathrm{C}$ from SSTA1 to SSTA2.

Semiannual variability found in oceanic and atmospheric variables around the JES (Section 1) motivated analysis of wind stress curl and its links with SSTA. Time series of the occurrence of $\mathrm{C} / \mathrm{AC}$ wind stress curl were introduced as follows. Every $1^{\circ}$-box was ascribed to a $\mathrm{C}$ (AC) curl case if the absolute curl value exceeded $0.5 \times 10^{-8}$ dyne $/ \mathrm{cm}^{3}$ and the curl was positive (negative). Otherwise, the box was ascribed to a weak wind case. Instantaneous occurrence was defined as a portion of boxes with $\mathrm{C} / \mathrm{AC}$ curl over the JES, not including the adjacent land mass. Time series of occurrence were computed from the NCEP/NCAR data set for 1998-2005 (Section 2). The occurrence of weak wind was computed in a similar way and is discussed for comparison. The original 6-h time series data contained noise and were thus filtered (reconstructed) using the inverse wavelet transform with the smallest period (scale) of 40 days. These time series, together with their local and global wavelet spectra, are presented in Fig. 10.

For the AC curl case (Fig. 10a), statistically significant spectral power was concentrated on the 6-month time scale, while a spectral minimum was evident on the 12month time scale (Fig. 10b, 10c). On average, the AC curl became more frequent in April-June and in September-October (Fig. 10a). There were two statistically significant spectral maxima in the occurrence of the $\mathrm{C}$ curl (Fig. 10d): (1) the highest maximum was on the 12month time scale and, (2) the secondary maximum occurred on the 6-month time scale (Fig. 10e, 10f). The C curl was most frequent in winter (Fig. 10d) in accordance with its prevalence in the winter wind patterns (Fig. 1e). One or two maxima of occurrence were present in late
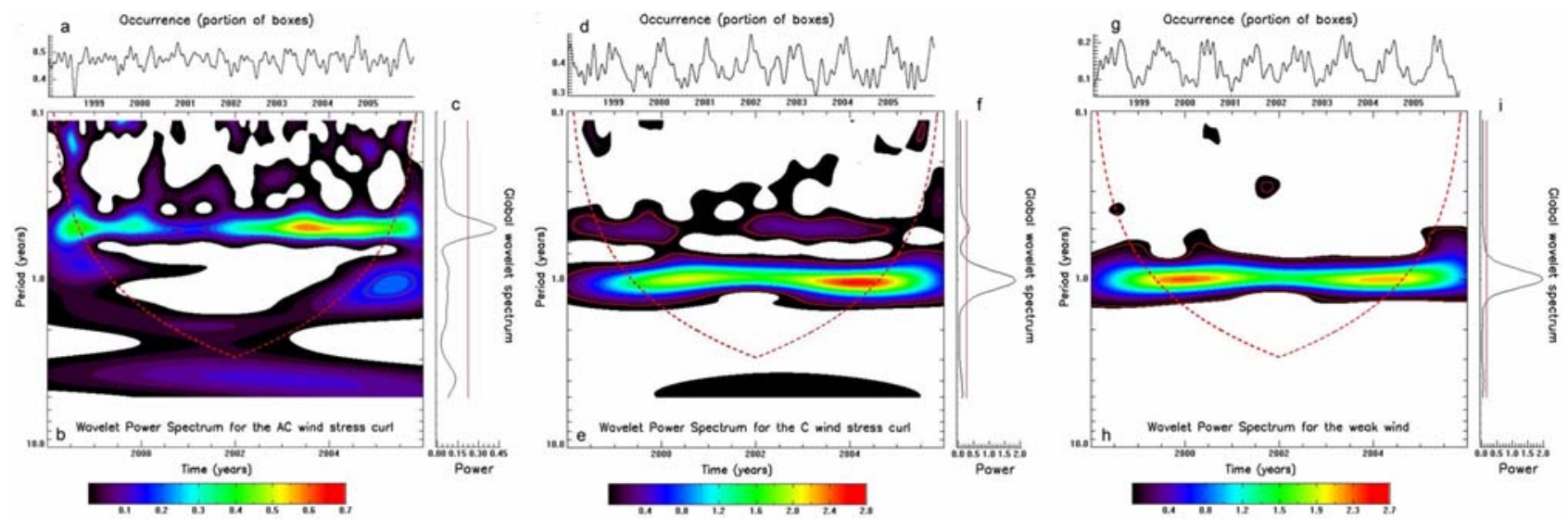

Fig. 10.(a) Wavelet-reconstructed time series and (b) local and (c) global wavelet power spectra of occurrence of AC wind stress curl. (d-f) Same as previous, except for the $C$ wind stress curl. (g-i) Same as previous, except for the weak wind. Local wavelet power is shown in white for values less than 0.05 . The COI is shown as red dashed contours. The $95 \%$ significance level estimated from the theoretical red noise spectrum is shown as solid red contours. 

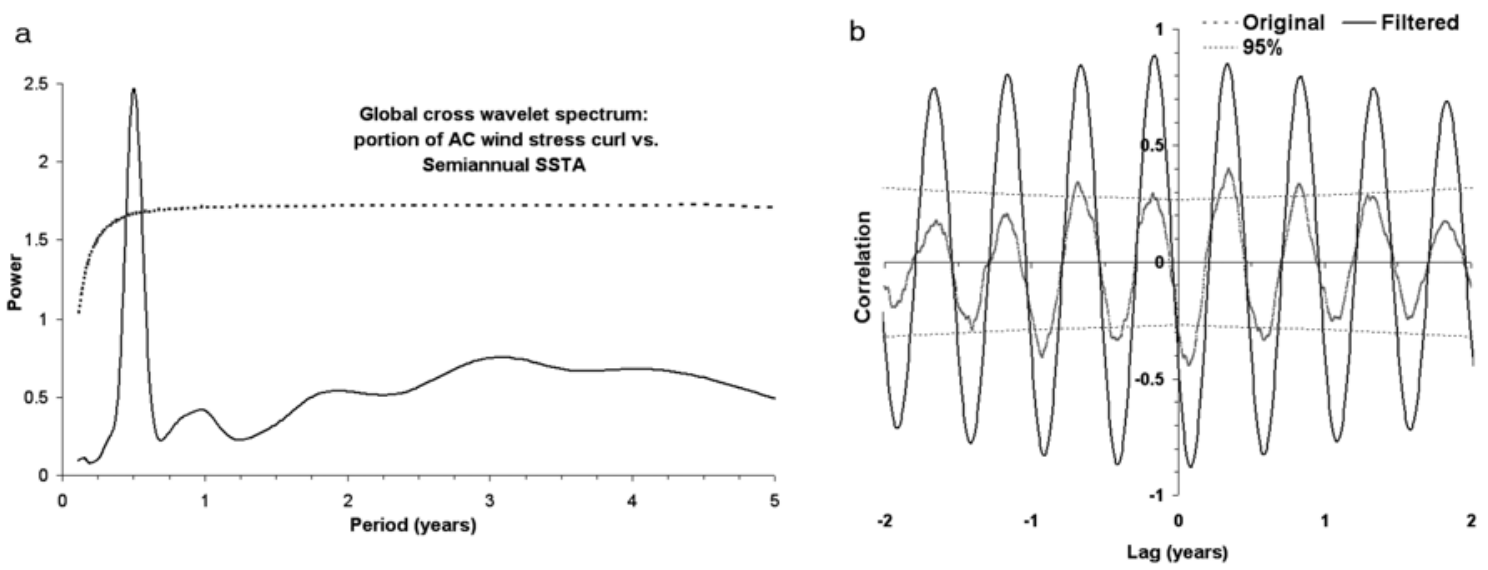

Fig. 11. (a) Global wavelet power cross-spectrum $\left({ }^{\circ} \mathrm{C}\right)$ between the occurrence of AC wind stress curl and the SSTA related to the Western Core of the Semiannual Mode. The $95 \%$ significance level estimated from the theoretical red noise spectrum is shown as a dashed line. (b) Lagged correlation between the same variables as in (a) for the original (gray line) and wavelet-filtered (black line) time series. Filtering was performed from 0.45 to 0.56 years. The time lag is in years with the wind (SSTA) leading at negative (positive) lags; the 95\% significance level is shown as dashed lines.

summer (July-August; Fig. 10d), in agreement with the increased occurrence of the easterly wind patterns (Fig. 2) characterized by the prevalence of the $C$ curl (Fig. 1f1h). The occurrences of $\mathrm{AC}$ and $\mathrm{C}$ curl revealed clear opposition to each other with a correlation of -0.67 . The 12-month time scale for the weak wind case (Fig. 10g10i) was consistent with the wind weakening in the warm season. The use of $0.25 \times 10^{-8} \mathrm{dyne} / \mathrm{cm}^{3}$ or $1.0 \times 10^{-8}$ dyne/ $\mathrm{cm}^{3}$ thresholds yielded similar results.

Linkages of the JES SST and wind were examined from wavelet cross-spectrum and lagged correlation (Fig. 11) between the JMA time series related to the Western Core of the Semiannual Mode (Fig. 8a) and the occurrence of the AC wind stress curl (Fig. 10a). The dominant semiannual time scale of the joint variability was evident from the global (Fig. 11a) and local (not shown) wavelet cross-spectra. The 0.45-0.56-year range of statistically significant cross-spectral power was chosen for band-pass filtering before calculating correlations. Correlation patterns for the original (gray line in Fig. 11b) and filtered (black line in Fig. 11b) time series confirmed the semiannual scale of the joint variability, with the coefficients being considerably larger for the filtered series (Fig. 11b). In both cases, the wind leading at the negative lags preceded SSTA by 2 months with a positive correlation of $0.3(0.88)$ for the original (filtered) time series. This means that the increased occurrence of the AC wind stress curl in spring and autumn was followed by SST increase in the Western Core and implies links between the Semiannual SST Mode and dynamic processes.

\section{Linkages of the Semiannual Mode to dynamic pro- cesses}

The Western Core extended along the SW and central branches of the thermal Subarctic Front (Fig. 12a). Nikitin (2007) showed that the SW Front shifts northward from May to June, so that the northward expansion of

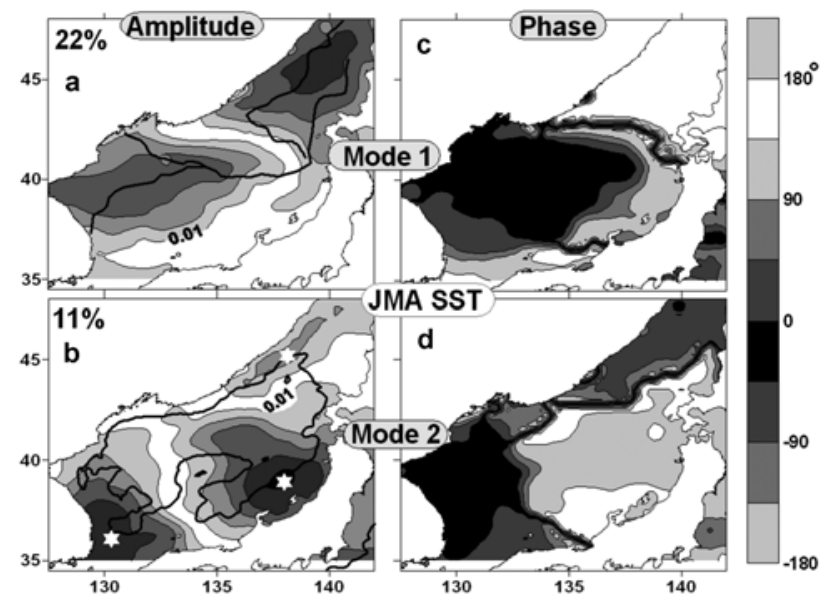

Fig. 12. Spatial amplitude (contours every 0.01) $(a, b)$ and phase $\left({ }^{\circ}\right)(c, d)$ of the Semiannual $(a, c)$ and Three-Core $(b, d)$ modes for JMA SSTA2. Asterisks show locations of characteristic time series in the EKWC, Honshu, and Primorye cores of the Three-Core Mode (b). Superimposed are (a) the branches of Subarctic Front (adopted from Nikitin 2007) and (b) 2000-m isobaths. 

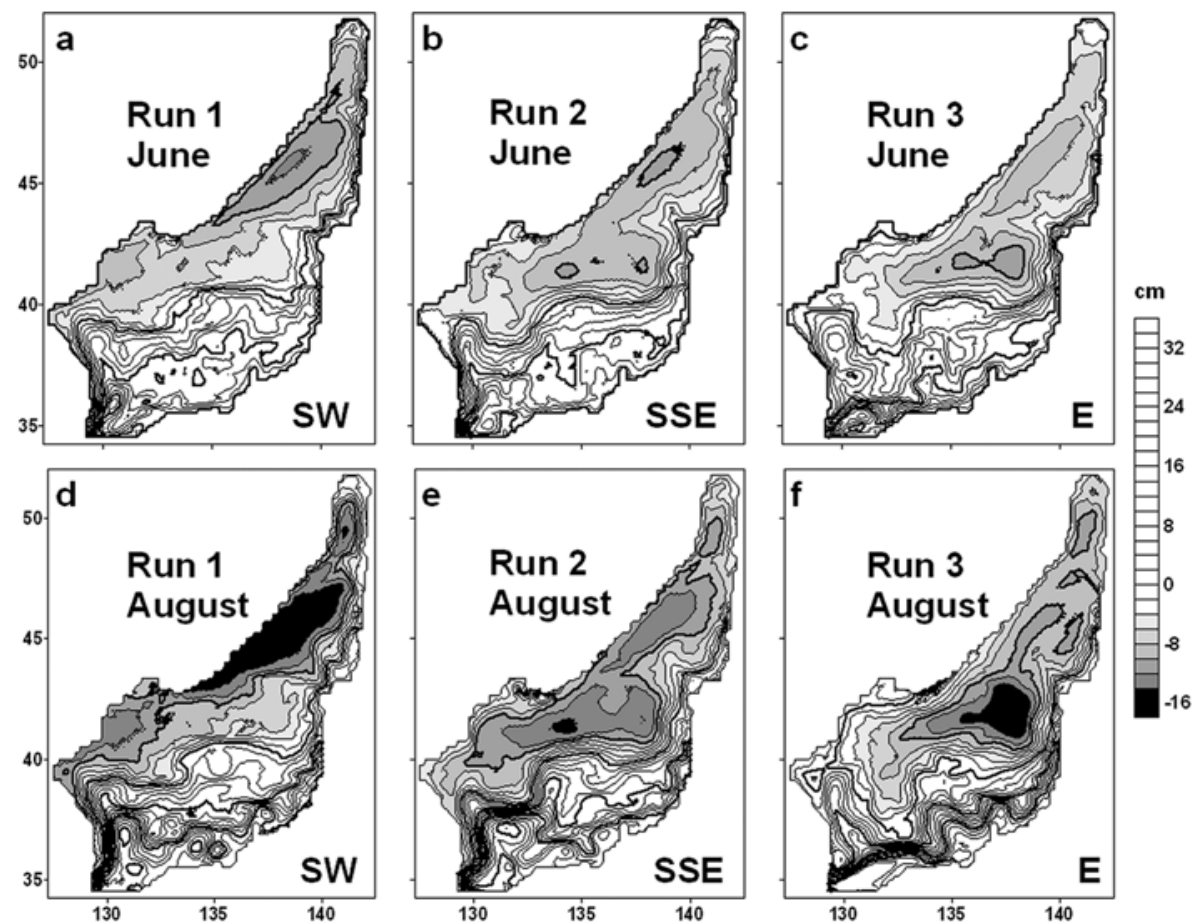

Fig. 13. Sea surface height $(\mathrm{cm})$ simulated under forcing of the $S W(a, d), \operatorname{SSE}(b, e)$, and $E$ wind patterns (c, f) for June (a-c) and August (d-f). Contours of 10, 0, 10, 20, and $30 \mathrm{~cm}$ are shown as thick lines. Hatches downhill.

warm water contributes to the spring maximum of the SST Semiannual Mode. The northward shift of Subarctic Front might be related to spring heating, increased transport in the Korea Strait, and strengthening of the AC circulation in the southwestern JES. Results from runs 13 suggest an important role of wind stress curl in the meridional migration of the Subarctic Front in the western JES between 130 and $134^{\circ} \mathrm{E}$. In Run 1, under the forcing of the alternating $\mathrm{C} / \mathrm{AC}$ curl in the warm season, the Subarctic Front was located in the northernmost latitude (Fig. 13a - June; Fig. 13d - August). It was located farther southward in Run 2 (Fig. 13b, 13e) under the forcing of the moderate $\mathrm{C}$ curl and reached the southernmost latitude in Run 3 under the forcing of the strong C curl (Fig. 13c, 13f).

In the early warm season (April-June), the SW wind patterns applied in Run 1 were more frequent than the SSE and E patterns applied in runs 2 and 3 (Fig. 2), in accordance with the increased occurrence of the AC curl over the entire JES (Fig. 10a). This implies that the AC wind stress curl facilitated the northward shift of the observed Subarctic Front in spring because other external conditions remained the same in runs 1-3 (Section 3). The autumnal extremum in the Semiannual Mode, which was weaker than that in spring, could be related to the formation of the NW branch of Subarctic Front (Sections 1 and 5). On the other hand, frequent $\mathrm{AC}$ curl over the JES in spring and autumn can induce formation of AC oceanic eddies and the formation intensifies in April and October (Nikitin 2007). Therefore, this process can contribute to the Semiannual Mode, although this is not evident from runs 1-3. Eddy-resolving simulations are needed to verify the eddy-related mechanism.

The Northern Core was stronger yet than the Western Core (Fig. 6b, 6e). Negative SSTA in the northernmost JES (Fig. 7b) could be related to cooler thermal conditions and the $\mathrm{C}$ circulation. However, that the Northern and Western cores belonged to the same Semiannual Mode implies some linked physical mechanism, such as forcing by the alternating $\mathrm{C} / \mathrm{AC}$ wind stress curl. As discussed in Section 2, there was a tendency toward curl opposition between the areas southward and northward of $42-46^{\circ} \mathrm{N}$ in the warm season. The AC curl prevailed over the southern area, while the $\mathrm{C}$ curl prevailed over the northern area in the westerly wind patterns and vice versa in the easterly patterns. Accordingly, the $\mathrm{C}$ gyre simulated northward of $43-44^{\circ} \mathrm{N}$ was strongest in Run 1 (Fig. 13a, 13d) under the forcing of the SW wind patterns (Fig. 1c, 1d). This gyre was weaker than the other $C$ gyres between 40 and $43^{\circ} \mathrm{N}$ in Run 2 (Fig. 13b, 13e) under the 
forcing of the SSE wind patterns (Fig. 1g). It was weakest in Run 3 (Fig. 13c, 13f) under the forcing of the E wind patterns (Fig. 1h). Considerable variability, including formation of warm eddies, was documented in the JES northward of $43-44^{\circ} \mathrm{N}$ from infrared satellite imagery (Nikitin 2007) and ship observations from the Pacific Scientific Research Fisheries Center (TINRO-Center), Vladivostok, Russia (Dyakov 2006a, 2006b).

\section{Three-Core Mode}

\section{Linkages of the Three-Core Mode to large-scale currents}

Mode 2 of SSTA2 was a counterpart of Mode 3 of SSTA1 (NGSST - Fig. 6c, 6i; Fig. 15b, 15d; JMASST Fig. 6f, 61; Fig. 12b, 12d). Corresponding eigenvalues satisfied North et al.'s (1982) criterion for the JMASST and NGSST data sets (Table 1), while lower SSTA2 modes did not reach the statistically significant level and corresponded to short-lived local signals and small-scale noise. The temporal amplitude of this mode slightly decreased from SSTA1 to SSTA2, but otherwise did not change. This mode had three spatial cores and is hereafter referred to as the Three-Core Mode.

The spatial pattern of the Three-Core Mode changed, to some extent, from SSTA1 (Fig. 6c, 6f) to SSTA2 (Fig. $12 \mathrm{~b}, 15 \mathrm{~b})$. Because the signal of the Adjustment Mode was removed from SSTA2, the amplitude in the western core was highest in the southwestern JES (in the area of the EKWC and related AC recirculation), particularly in the well-known Ulleung Warm Eddy (Chang et al. 2004). This core is hereafter referred to as the EKWC Core. The northern Primorye Core extended near the continental coast along the path of the Primorye (Liman) Current (Fig. 12b, 15b). The eastern (Honshu) Core occupied a vast area, expanding toward the northern Yamato Rise, where mesoscale eddies generated by the Tsushima Current were observed (Toba et al. 1984). In the pattern obtained from the JMA data set, amplitude in the Honshu Core was highest over the slope off Noto Peninsula, shown by 2000-m isobaths (Fig. 12b). Thus, the ThreeCore Mode was related to the large-scale currents transporting warm or cold water.

Characteristic time series for every core were computed from the JMASST data set (Fig. 14) in the locations shown by asterisks in Fig. 12b. Positive (negative) SSTA developed in the Honshu (EKWC and Primorye) cores in late summer (July-August) and could persist through autumn. The SSTA in the Honshu and EKWC cores exceeded $1{ }^{\circ} \mathrm{C}$ in their extrema. In contrast, the SSTA in the Primorye Core was weaker, as suggested by the spatial pattern (Fig. 12b), and was mostly less than $1{ }^{\circ} \mathrm{C}$ by magnitude. However, the interpretable spatial pattern justified the consideration of the Primorye Core. Simultaneous positive SSTA in the Honshu Core and negative SSTA in the Primorye Core imply the synchronized strengthening of the Tsushima Current in the southeastern JES and of the Primorye Current (northward of $44^{\circ} \mathrm{N}$ ). Negative SSTA in the EKWC Core corresponded to the simultaneous weakening of the EKWC in the southwestern JES. Weaker opposite SSTA developed in spring (Fig. 14), consistent with the spring extremum of the Semiannual Mode (Section 6).

Results from runs 1-3 suggested variability of the wind-driven circulation as a possible dynamic forcing of the SSTA related to the Three-Core Mode. The simulated EKWC formed the AC recirculation gyre after its separation from the coast with the formation, in some cases, of a closed eddy corresponding to the Ulleung

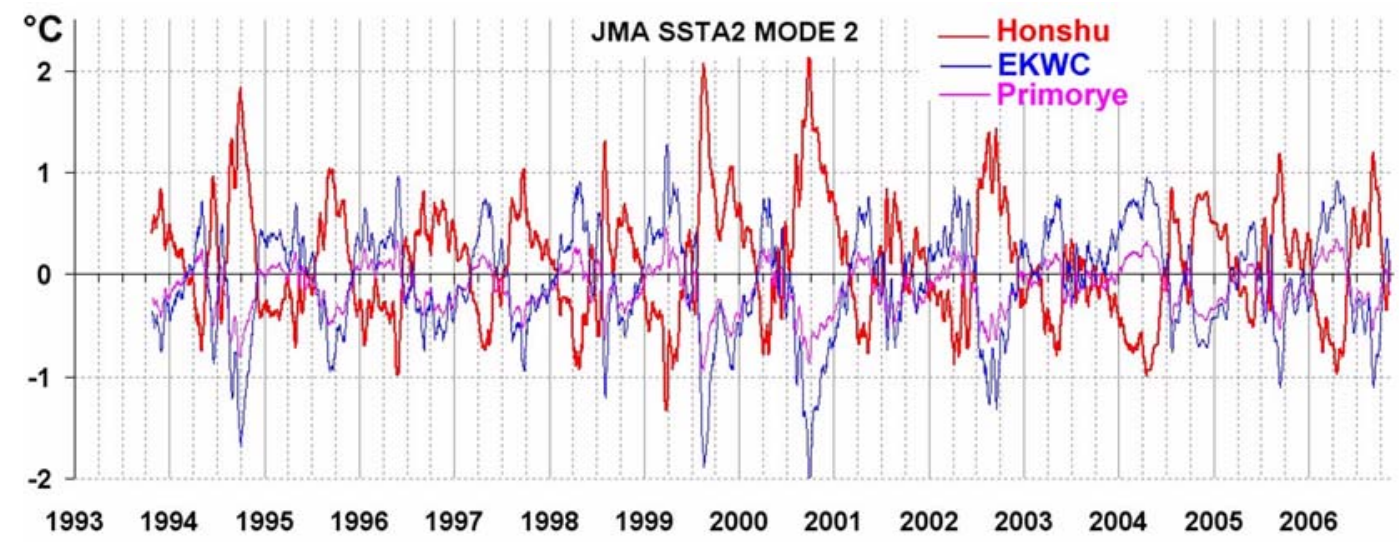

Fig. 14. Characteristic time series $\left({ }^{\circ} \mathrm{C}\right)$ related to the Three-Core Mode for JMA SSTA2 in the Honshu (red line), EKWC (blue line), and Primorye (magenta line) cores at the locations shown in Fig. 12b. 
Warm Eddy (Fig. 13 - June and August). The EKWC and the AC recirculation in the western JES weakened from Run 1 to Run 3 with the strengthening of the $C$ wind stress curl. At the same time, the $\mathrm{C}$ wind stress curl induced the southward shift of the Subarctic Front and the southward expansion of cold water from the subarctic region to the southwestern JES (Section 6). Weakening of the EKWC in the western JES was accompanied by the strengthening of the Tsushima Current in the southeastern JES (Fig. 13). The latter implies the increased transport of warm water northward along the coast of Honshu. The easterly SSE and E wind patterns (Fig. 2g, 2h) and the C stress curl over the entire JES (Fig. 10d) became more frequent by late summer, and the circulation patterns from Run 2 or Run 3 seemed more typical in late summer.

The Three-Core Mode revealed considerable interannual variability (Fig. 8h, 8i), and the summer-autumn signal was strongest in 1994, 1999, and 2000 (Fig. 14). There were no anomalies related to this mode in summerautumn 2003. This accounts for the difference between the patterns obtained from the JMASST and NGSST data sets (Fig. 12b, 15b), as NGSST started from July 2002 and covered the period of weak and moderate signal (Fig. 14). Variability was extremely high in the southwestern JES; in particular, the EKWC, which was once considered a permanent feature, could weaken or even disappear. The EKWC was weak from June 1999 to June 2001 and completely disappeared from mid-June to early November 2000 (Chang et al. 2004). This is consistent with the strong negative SSTA in the EKWC Core in summer 1999 and 2000 (Fig. 14). The physical causes of interannual variability of the Three-Core Mode are not yet clear and require further research.

\section{Standing vs. moving signal in the Three-Core Mode}

NGSST revealed an intriguing feature of moving anomalies. The Honshu and Primorye cores are connected by an amplitude belt curved along the northern flank of the Japan Basin (along the 2000-m isobaths in Fig. 15d). The spatial phase gradually increased along this path by almost $180^{\circ}$ as shown by a white arrow in Fig. 15d. Anomalies can move only when the temporal phase gradually increases (Section 2). The temporal phase did not change much between October 2002 and May 2004 (Fig. 15e) when the SSTA related to the Three-Core Mode was weak (Fig. 7c, 14). Several events occurred in July-September 2002, 2004, and 2005 (shown by arrows in Fig. 15e) when the temporal phase gradually increased and the SSTA moved from the Honshu Core to the

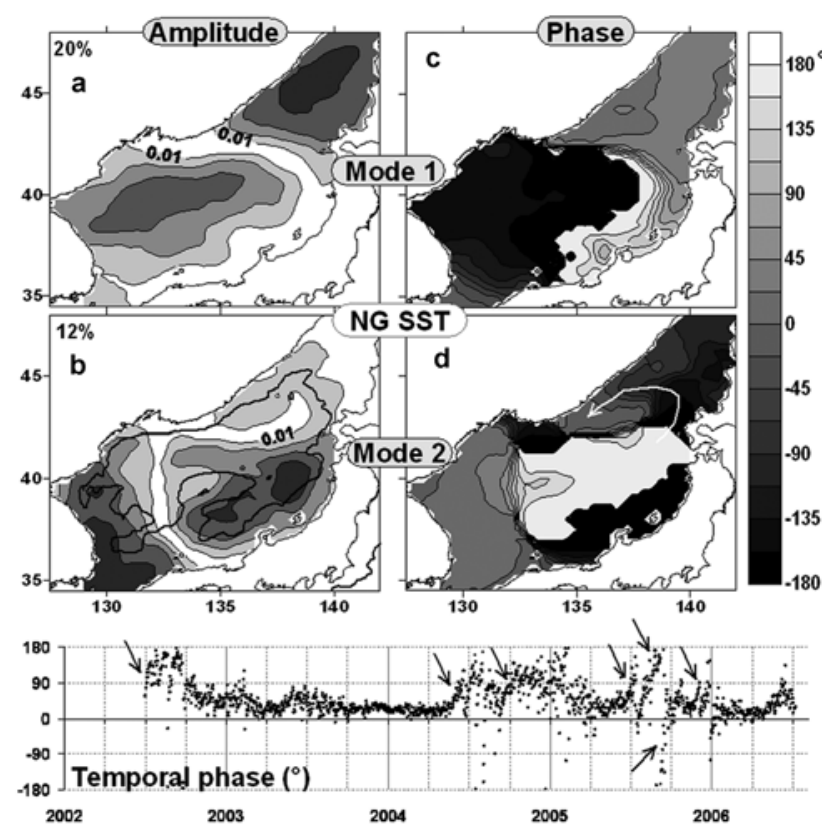

Fig. 15. Spatial amplitude (contours every 0.01) (a, b) and phase $\left({ }^{\circ}\right)(c, d)$ of the Semiannual $(a, c)$ and Three-Core $(b, d)$ modes for NG SSTA2. (e) Temporal phase of the Semiannual Mode for NG SST ( ${ }^{\circ}$ ). (b) Superimposed are 2000-m isobaths. Arrows show (e) events and (d) the path of SSTA movement.

\section{Primorye Core.}

Patterns of instantaneous SSTA related to the ThreeCore Mode (Section 2) for the most pronounced movement event in July-September 2005 are presented in Fig. 16. In mid-July, the standing oscillation was in the reversed phase, typical for spring, with negative (positive) SSTA in the Honshu (EKWC and Primorye) cores. Negative SSTA moved westward from the Honshu Core to the Primorye Core from mid- through late July. Afterwards, the phase of the standing oscillation changed, and the positive SSTA moved westward from late August through September (Fig. 16). The average speed of the moving SSTA could be estimated for this event from Eq. (2), giving an estimated characteristic length scale $\mathrm{L}$ along the path (white arrow in Fig. 15d) of $500 \mathrm{~km}$, a characteristic period $\mathrm{T}$ of 90 days, and spatial phase increment $(\Delta \theta)$ of $160^{\circ}$, which yielded a speed $\mathrm{V}$ of about $15 \mathrm{~cm} / \mathrm{s}$.

The path of SSTA movement corresponded to the northern edge of the $\mathrm{C}$ gyre simulated over the eastern Japan Basin (Fig. 13). A current often referred to as the westward branch of the Tsushima Current flows westward along this edge (Danchenkov et al. 2006). The eastern C gyre was strongest in Run 3 under the forcing of the 

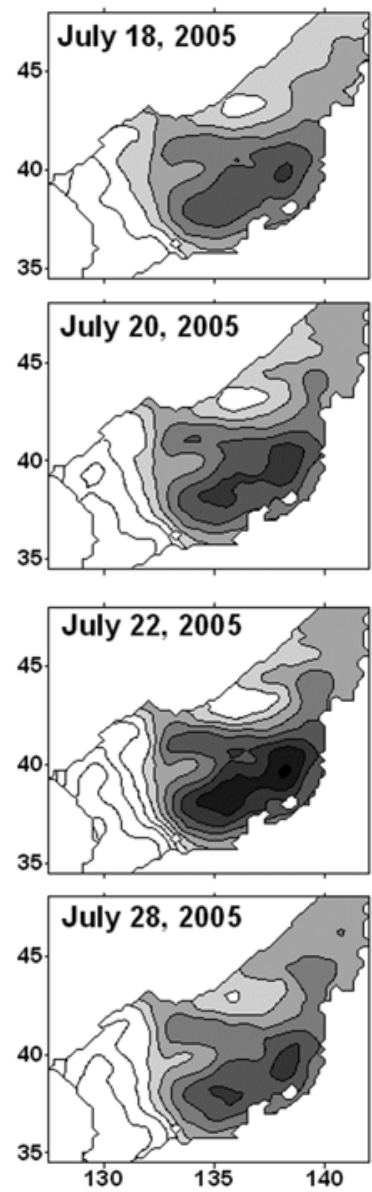
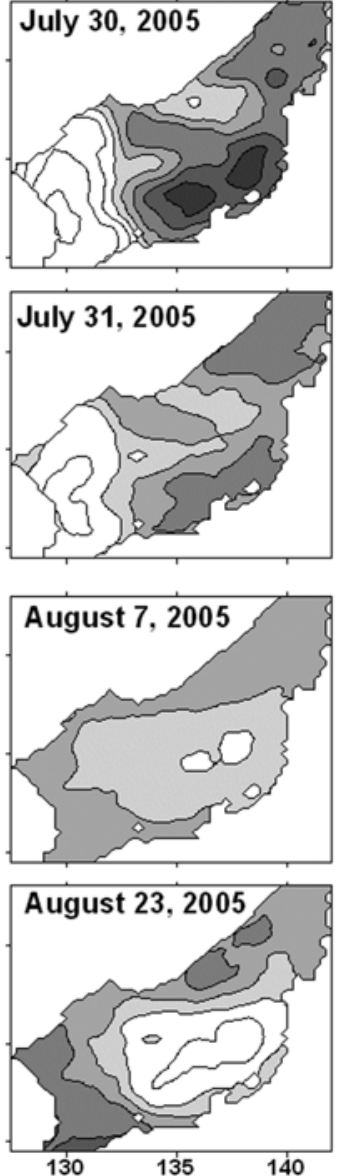
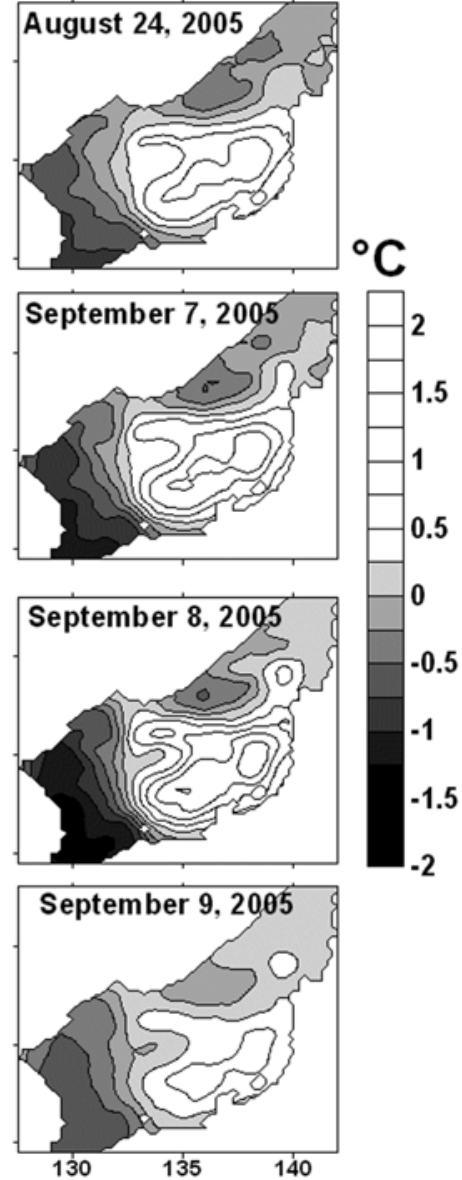

Fig. 16. Instantaneous fields of NG SSTA2 related to the Three-Core Mode from 18 July 2005 to 9 September 2005.

strong C curl (Fig. 13c, 13f), more typical for late summer, as discussed above. Events of SSTA movement occurred in late summer, too, and the estimated speed corresponded to the advective scale. Good quality data coverage with few gaps throughout the whole duration of NGSST made it possible to detect moving SSTA even for moderately strong events.

\section{Conclusion}

Variability of the JES SST was analyzed using CEOF analysis of two daily data sets with fine spatial resolution: (1) NGSST from Tohoku University, Japan (July 2002July 2006), and (2) subset of MGDSST (October 1993November 2006). CEOFs were derived as eigenvectors of the correlation matrix rather than from more common covariances (Hannachi et al. 2007). The normalization provided by correlations facilitated identification of lowamplitude SSTA in the northern JES. Anomalies were calculated by removing the seasonal signal obtained as the leading mode of the original SST. The NCEP/NCAR 6-h $1^{\circ}$-gridded surface zonal and meridional winds (1998-2005), SeaWiFS Project ancillary data, were used for joint analysis with SST.

Three leading SSTA modes obtained from both data sets were statistically significant and consistent with each other. Time scales were estimated at the $95 \%$ level of statistical significance using wavelet analysis (Torrence and Compo 1998). Mode 1 oscillated on the 12-month time-scale and provided the largest contribution to SST in late December. This mode can be considered as an adjustment (addition) to the average seasonal signal; it was positive in the southern JES and negative in the northwestern JES, in accordance with the findings of Park et al. (2005). The adjustment magnitude was largest in the area of warm water entering the JES through the Korea Strait and in the NW area of the $\mathrm{C}$ wind stress curl (in winter) southeastward of Vladivostok.

Mode 2 was characterized by dominant semiannual and quasi-biennial time scales, providing the largest contribution to SST in May-June and November-December. The spatial pattern represented a seesaw between the area 
around the Subarctic Front in the western JES and the northernmost area (northward of $42^{\circ} \mathrm{N}$ ), where the SSTAs related to Mode 2 were positive and negative, respectively. The SSTA related to this mode reflected the joint semiannual variability with the wind stress curl over the JES. Positive SSTA around the western Subarctic Front lagged 2 months behind the increased occurrence of the $\mathrm{AC}$ curl. In the warm season, the wind curl over the northernmost JES was opposite to the curl over the central JES; when the AC curl prevailed over the central JES, the C curl was frequent over the northernmost JES and vice versa. Negative SSTA northward of $42^{\circ} \mathrm{N}$ was linked to the local $\mathrm{C}$ wind stress curl.

The 12-month and quasi-biennial time scales dominated in Mode 3. The three spatial cores were located (1) off Honshu within the area of the Tsushima Current and related warm eddies, (2) within the EKWC and related AC circulation, including the Ulleung Warm Eddy, and (3) within the Primorye (Liman) Current along the continental coast northward of $44^{\circ} \mathrm{N}$. Positive (negative) SSTA developed in the Honshu (EKWC and Primorye) cores with the largest magnitude in late summer-autumn. Weak SSTA of the opposite sign developed in spring. Events of west-east SSTA movement were identified in July-September 2002, 2004, and 2005. The SSTA related to Mode 3 moved from the northeastern JES towards the continental coast along the path of the westward branch of the Tsushima Current with a speed of $\sim 15 \mathrm{~cm} / \mathrm{s}$. This speed is consistent with the advective scale.

Linkages to wind stress curl and circulation features imply an impact of dynamic processes upon SST. To support this hypothesis, numerical simulations were performed using a primitive equation oceanic model (Mikhaylova and Shapiro 1993; Shapiro 2000). Wind forcing was provided by typical patterns distinguished by the prevailing wind direction and curl spatial distribution (Trusenkova et al. 2007). The response of the simulated circulation to different kinds of wind forcing was analyzed to suggest dynamic processes responsible for the SSTA formation. These possible processes include the inflow of warm water through the Korea Strait, divergence in the surface layer induced by Ekman suction, southward (northward) shift of Subarctic Front forced by C (AC) wind stress curl, AC eddy formation in the western JES under the forcing of the AC curl, and wind-driven strengthening/weakening of the large-scale currents. The wind-driven strengthening/weakening signifies that the Tsushima Current in the southeastern JES and the Primorye Current northward of $44^{\circ} \mathrm{N}$ strengthen (weaken) together with the weakening (strengthening) of the EKWC in the southwestern JES. To confirm the suggested physical mechanisms, EOF analysis of SST simulated under different kinds of wind forcing will be performed as a continuation of this study. Eddy-resolving simulations using fine spatial grids and forced by fine-resolution winds derived from satellite altimetry data (QuikSCAT winds) are necessary to confirm the impact of mesoscale processes.

\section{Acknowledgements}

The authors would like to express the sincere gratitude to KORDI for the organization of the 3rd KORDI - POI Workshop, 2007, and kind hospitality. The authors would like to thank Prof. H. Kawamura, Tohoku University, Japan, for providing the NGSST data. We also thank our colleagues from the Marine Hydrophysical Institute, Sebastopol, Ukraine: Drs. S. Stanichny and Yu. Ratner for preparation of the wind data and Prof. N.B. Shapiro and Dr. E.N. Mikhaylova for providing the oceanic model and numerous consultations.

\section{References}

Chang KI, Teague WJ, Lyu SJ, Perkins HT, Lee D-K, Watts DR, Kim Y-B, Mitchell DA, Lee CM, Kim K (2004) Circulation and currents in the southwestern East/ Japan Sea: overview and review. Progr Oceanogr 61:105156

Danchenkov MA, Lobanov VB, Nikitin AA (1997) Mesoscale eddies in the Japan Sea, their role in circulation and heat transport. In: Proceedings of the CREAMS-97 International Symposium, Fukuoka, Japan, pp 81-84

Danchenkov MA, Lobanov VB, Riser SC, Kim K, Takematsu M, Yoon J-H (2006) A history of physical oceanographic research in the Japan/East Sea. Oceanogr 19(3): 18-31

Dyakov BS (2006a) Year-to-year variability of water circulation in the Tatar Strait in summer. Izv TINRO 144: 281-299 (in Russian)

Dyakov BS (2006b) On water circulation in the Tatar Strait in spring. Izv TINRO 146:205-212 (in Russian)

Ginzburg AI, Kostyanoy AG, Ostrovskii AG (1998) Surface circulation of the Japan Sea (satellite information and drifters data). Issledovaniya Zemli iz Kosmosa (Earth Research from Space) 1:66-83 (in Russian)

Guan L, Kawamura H (2004) Merging satellite infrared and microwave SSTs: Methodology and evaluation of the new SST. J Oceanogr 60:905-912

Hannachi A, Jolliffe IT, Stephenson DB (2007) Empirical orthogonal functions and related techniques in atmospheric science: a review. Int J Climatol 27(9):11191152 
Hosoda K, Kawamura H (2004) Examination of the merged sea surface temperature using wavelet analysis. J Oceanogr 60:943-852

Isoda Y, Saitoh S (1993) The northward intruding eddy along the east coast of Korea. J Oceanogr 49:443-458

Kawamura H, Wu P (1998) Formation mechanism of the Japan Sea proper water in the flux center off Vladivostok. J Geophys Res 99(C12):553-574

Koldunov VV, Staritsin DK, Foux VR (2007) Variability of sea level in the Japan and Okhotsk seas by satellite altimetry data. In: Lobanov VB, Luchin VA (eds) Far Eastern Seas of Russia, Book 1: Oceanological studies, Nauka, Moscow (in Russian), pp 184-231

Leonov AK (1960) Regionalnaya Oceanographiya, Chast 1 (Regional Oceanography, Part I). Gidrometeoizdat, Moscow, Russia, 765 p (in Russian)

Lobanov VB, Ponomarev VI, Salyuk AN, Tishchenko PY, Talley LD (2007) Structure and dynamics of synoptic scale eddies in the northern Japan Sea. In: Lobanov VB, Luchin VA (eds) Far Eastern Seas of Russia, Book 1: Oceanological studies, Nauka, Moscow (in Russian), pp 450-473

Mikhaylova EN, Shapiro NB (1993) Quasi-isopycnic layer model of large-scale ocean circulation. Phys Oceanogr 4(4):251-261

Minobe S, Sako A, Nakamura M (2004) Interannual to interdecadal variability in the Japan Sea based on a new gridded upper water temperature dataset. J Phys Oceanogr 34:2382-2397

Nikitin AA (2007) Thermal fronts and eddies in the Japan Sea. Ph.D. Thesis, Pacific Fisheries Center, Vladivostok, Russia, 197 p (in Russian)

North GR, Bell TL, Cahalon RF, Moeng FJ (1982) Sampling errors in the estimation of empirical orthogonal functions. Mon Wea Rev 110:699-706

Palshin NA, Vanyan LL, Medzhitov RD, Shapiro GI, Evdoshenko MA, Utada H, Shimizu H, Tanaka Y (2001) Use of the Nakhodka-Naoetsu submarine cable for studying the temporal variability of the integral water transport in the Sea of Japan. Oceanology 41:447-453

Park K-A, Chung JY (1999) Spatial and temporal scale variations of sea surface temperature in the East Sea using NOAA/AVHRR data. J Oceanogr 55:271-288

Park K-A, Chung JY, Kim K, Cornillon PC (2005) Wind and bathymetric forcing of the annual sea surface temperature signal in the East (Japan) Sea. Geophys Res Let 32:L05610. doi:10.1029/2004GL022197
Park S, Chu P (2006) Interannual SST variability in the Japan/East Sea and relationship with environmental variables. J Oceanogr 62(2):115-132

Quadrelli R, Bretherton CS, Wallace JM (2005) On sampling errors in empirical orthogonal functions. J Climate 18:3704-3710

Sakurai T, Yukio K, Kuragano T (2005) Merged satellite and in-situ data global daily SST. In: Proceedings of Geoscience and Remote Sensing Symposium, IGARSS '05, IEEE International 4, pp 2606-2608

Sedov VE (1990) Semiannual cycles in sea level pressure in middle and high northern latitudes. Meteorologiya i Gidrologiya (Meteorol Hydrol) 6:45-51 (in Russian)

Shapiro NB (2000) Formation of a circulation in the quasiisopycnic model of the Black Sea taking into account the stochastic nature of the wind stress. Phys Oceanogr 11(1):11-28

Sugimoto T, Tameishi H (1992) Warm core rings, streamers and their role on the fishing ground formation around Japan. Deep-Sea Res 39 (Suppl):183-201

Takikawa T, Yoon J-H (2005) Volume transport through the Tsushima Straits estimated from sea level difference, J Oceanogr 61:699-708

Toba Y, Kawamura H, Yamashita F, Hanawa K (1984) Structure of horizontal turbulence in the Japan Sea. In: Ichiye $\mathrm{T}$ (ed) Ocean hydrodynamics of the Japan and East China Seas, Elsevier, Amsterdam, pp 317-332

Torrence C, Compo GP (1998) A practical guide to wavelet analysis. Bull Amer Meteorol Soc 79(1):61-78

Trusenkova O, Ishida H (2005) Seasonal variation of surface and deep currents in the Japan Sea. J Hydrau Coast Environ Eng JSCE, 796/II-72:93-111

Trusenkova OO, Stanichnyi SV, Ratner Y (2007) Major variability modes and wind patterns over the Sea of Japan and adjacent areas. Izv Atmos Oceanic Phys 43(5):634-648

Yashaev IM, Zveryaev II (2001) Climate of the seasonal cycle in the North Pacific and North Atlantic Ocean. Int J Climatol 21:401-417

Yoon J-H, Abe K, Ogata T, Wakamatsu Y (2005) The effects of wind-stress curl on the Japan/East Sea circulation. Deep-Sea Res II 52:1827-1844

Received Feb. 4, 2008

Revised Mar. 11, 2008

Accepted Oct. 13, 2008 